Linköping Studies in Science and Technology. Dissertations No. 2023

\title{
Modelling of Crack Growth in Single-Crystal Nickel-Base Superalloys
}

\section{Christian Busse}


Linköping Studies in Science and Technology.

Dissertations No. 2023

\title{
Modelling of Crack Growth in Single-Crystal Nickel-Base Superalloys
}

\author{
Christian Busse
}


Cover:

SEM image of the transition of cracking modes.

Printed by:

LiU-Tryck, Linköping, Sweden, 2019

ISBN: 978-91-7929-983-5

ISSN: 0345-7524

Distributed by:

Linköping University

Solid Mechanics

SE-581 83 Linköping, Sweden

\section{(C) 2019 Christian Busse}

This document was prepared with LATEX, November 12, 2019

No part of this publication may be reproduced, stored in a retrieval system, or be transmitted, in any form or by any means, electronic, mechanical, photocopying, recording, or otherwise, without prior permission of the author. 


\section{Preface}

The work presented in this dissertation has been generated at the Division of Solid Mechanics at Linköping University. The first part of the research project has been funded by the Swedish Energy Agency and Siemens Industrial Turbomachinery AB through the Research Consortium of Materials Technology for Thermal Energy Processes, Grant no. KME-702, the support of which is greatly acknowledged. During this time papers I, II, III and VI have been produced. The remaining part of the research project, which included papers IV and $\mathbf{V}$, has been funded by Linköping University. The research project concerns the fields of mechanical testing, microstructure investigations and modelling. This broad spectrum gave me the opportunity to learn something new almost every day.

This said, I would especially like to thank my main supervisor Associate Prof. Daniel Leidermark, who has always had an open door and took himself the time to help with everything I had on my mind. With his caring and supporting character he is probably the best supervisor one could ask for. Furthermore, I would like to thank my project group; Prof. Kjell Simonsson, Lic. Eng. Björn Sjödin, Lic. Eng. Per Almroth, Dr. David Gustafsson, Prof. Johan Moverare and Lic. Eng. Frans Palmert, and Dr. Paul Wawrzynek for all the valuable discussions and input.

Furthermore, I would like to thank my friends and fellow PhD students at the division, who helped me with many fruitful discussions and made the $\mathrm{PhD}$ life more fun. A particular thank you goes to my office mate and friend J-L for his help with everything. A special thanks also to Jordi with whom I shared many memorable work trips and who has been a great friend through the years.

Finally, I would like to thank my parents for their great support through the years, and also my girlfriend Mikaela who came into my life last year and since then has always been there for me and supported me with all she could.

Thank you!

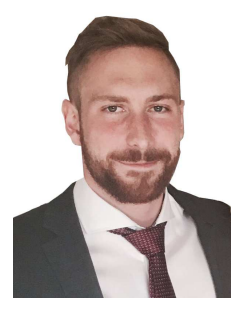

Linköping, December 2019

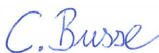

Christian Busse 

The nature of science is not that of a steady, linear progression toward the truth, but rather a tortuous road, often characterized by dead ends and U-turns, and yet ultimately inching toward a better, if tentative, understanding of the natural world. - Massimo Pigliucci 



\section{Abstract}

This dissertation was produced at the Division of Solid Mechanics at Linköping University and is part of a research project, which comprises modelling, microstructure investigations and material testing of cast nickel-base superalloys.

The main objective of this work was to deepen the understanding of the fracture behaviour of single-crystal nickel-base superalloys and to develop a model to predict the fatigue crack growth behaviour. Frequently, crack growth in these materials has been observed to follow one of two distinct cracking modes; Mode I like cracking perpendicular to the loading direction or crystallographic crack growth on the octahedral $\{111\}$-planes, where the latter is associated with an increased fatigue crack growth rate. Thus, it is of major importance to account for this behaviour in component life prediction. Consequently, a model for the prediction of the transition of cracking modes and the correct active crystallographic plane, i.e. the crack path, and the crystallographic crack growth rate has been developed. This model is based on the evaluation of appropriate crack driving forces using three-dimensional finite element simulations. A special focus was given towards the influence of the crystallographic orientation on the fracture behaviour. Further, a model to incorporate residual stresses in the crack growth modelling is presented. All modelling work is calibrated and validated by experiments on different specimen geometries with different crystallographic orientations.

This dissertation consists of two parts, where Part I gives an introduction and background to the field of research, while Part II consists of six appended papers. 



\section{Zusammenfassung}

Die vorliegende Dissertation wurde in der Abteilung für Festigkeitslehre an der Universität von Linköping erstellt und ist Teil eines Forschungsprojektes, welches Modellierung, Mikrostrukturuntersuchungen und Materialtests von gegossenen nickelbasierten Superlegierungen umfasst.

Das Hauptziel dieser Arbeit war es, das Verständnis des Bruchverhaltens von einkristallinen Superlegierungen auf Nickelbasis zu vertiefen und ein Modell zur Vorhersage des Wachstumsverhaltens von Ermüdungsrissen zu entwickeln. Es wurde beobachtet, dass das Risswachstum in diesen Materialien einem von zwei unterschiedlichen Rissmodi folgt; Modus I Rissfortschritt senkrecht zur Belastungsrichtung oder kristallographisches Risswachstum auf den oktaedrischen $\{111\}$-Ebenen, wobei letzteres mit einer erhöhten Ermüdungsrisswachstumsrate verbunden ist. Somit ist es von großer Bedeutung dieses Verhalten in der Lebensdauervorhersage einer Komponente zu berücksichtigen. Demzufolge wurde ein Modell für die Vorhersage des Übergangs zwischen den Rissmodi und der korrekten aktiven kristallographischen Ebene, d.h. des Risspfades, sowie der kristallographischen Risswachstumsrate erarbeitet. Dieses Modell basiert auf geeigneten Rissantriebskräften, welche mit Hilfe dreidimensionaler Finite-Elemente-Simulationen berechnet werden. Im Fokus stand insbesondere der Einfluss der kristallographischen Orientierung auf das Bruchverhalten. Außerdem wird ein Modell zur Berücksichtigung von Restspannungen in der Risswachstumsmodellierung präsentiert. Alle Modellierungsarbeiten wurden durch Experimente an verschiedenen Probengeometrien mit unterschiedlichen kristallographischen Orientierungen kalibriert und validiert.

Diese Dissertation besteht aus zwei Teilen, wobei Teil I aus einer Einführung und einem Hintergrund in das Forschungsgebiet und Teil II aus sechs beigefügten Forschungsartikeln besteht. 



\section{Sammanfattning}

Denna avhandling producerades på Avdelningen för Mekanik och Hållfasthetslära vid Linköpings universitet och är en del av ett forskningsprojekt som omfattar modellering, mikrostrukturundersökningar och materialprovning av gjutna nickelbaserade superlegeringar.

Huvudsyftet med detta arbete var att fördjupa förståelsen för sprickbeteendet i enkristallina nickelbaserade superlegeringar och att utveckla en modell för att prediktera tillväxtbeteendet hos utmattningssprickor. Ofta har spricktillväxten i dessa material observerats att följa en av två distinkta sprickmoder; Modus I, vinkelrätt mot lastningsriktningen, eller kristallografisk sprickväxt på oktaedra $\{111\}$-plan, där det senare är förknippat med en ökad utmattningssprickväxthastighet. Det är alltså av största vikt att ta hänsyn till detta beteende vid analys av en komponents livslängd. Således har en modell för prediktering av övergången mellan sprickmoder och aktivt kristallografiskt plan, dvs. sprickvägen, och den kristallografiska sprickväxthastigheten utvecklats. Denna modell är baserad på utvärderingen av lämpliga sprickdrivkrafter med hjälp av tredimensionella finita element simuleringar. Särskilt fokus gavs till påverkan av den kristallografiska orienteringen på sprickbeteendet. Vidare presenteras en modell för att integrera restspänningar i spricktillväxtsmodelleringen. Allt modelleringsarbete kalibrerades och validerades genom experiment på olika provstavsgeometrier med olika kristallografiska orienteringar.

Denna avhandling består av två delar, där Del I ger en introduktion och bakgrund till forskningsområdet, medan Del II består av sex inkluderade artiklar. 



\section{List of papers}

In this dissertation, the following papers have been included:

I. C. Busse, J. Homs, D. Gustafsson, F. Palmert, B. Sjödin, J.J. Moverare, K. Simonsson, D. Leidermark (2016). A finite element study of the effect of crystal orientation and misalignment on the crack driving force in a singlecrystal superalloy, Proceedings of the ASME Turbo Expo, Volume 7A-2016

II. C. Busse, F. Palmert, B. Sjödin, P. Almroth, D. Gustafsson, K. Simonsson, D. Leidermark (2018). Prediction of crystallographic cracking planes in a single-crystal nickel-base superalloy, Engineering Fracture Mechanics, Volume 196, pp. 206-223

III. C. Busse, F. Palmert, B. Sjödin, P. Almroth, D. Gustafsson, K. Simonsson, D. Leidermark (2019). Evaluation of the crystallographic fatigue crack growth rate in a single-crystal nickel-base superalloy, International Journal of Fatigue, Volume 127, pp. 259-267

IV. C. Busse, D. Gustafsson, F. Palmert, B. Sjödin, P. Almroth, J.J. Moverare, K. Simonsson, D. Leidermark (2019). Criteria evaluation for the transition of cracking modes in a single-crystal nickel-base superalloy, Submitted

V. C. Busse, F. Palmert, D. Gustafsson, P. Almroth, B. Sjödin, K. Simonsson, D. Leidermark (2019). Challenges in crack propagation prediction in single-crystal nickel-base superalloys, $13^{\text {th }}$ International Conference on the Mechanical Behaviour of Materials, Accepted for publication

VI. C. Busse, D. Gustafsson, P. Rasmusson, B. Sjödin, J.J. Moverare, K. Simonsson, D. Leidermark (2015). Three-dimensional LEFM prediction of fatigue crack propagation in a gas turbine disc material at component near conditions, Journal of Engineering for Gas Turbines and Power, Volume 138, Issue 4, Article Number 042506

\section{Note:}

The published appended papers have been reprinted with the permission of the respective copyright holders and all appended papers have been reformatted to fit the layout of the dissertation. 
Not included in this dissertation:

VII. C. Busse, F. Palmert, P. Wawrzynek, B. Sjödin, D. Gustafsson, D. Leidermark (2018). Crystallographic crack propagation rate in single-crystal nickel-base superalloys, MATEC Web of Conferences, 12th International Fatigue Congress, Volume 165, Article Number 13012

VIII. F. Palmert, J.J. Moverare, D. Gustafsson, C. Busse (2018). Fatigue crack growth behaviour of an alternative single crystal nickel base superalloy, International Journal of Fatigue, Volume 109, pp. 166-181

\section{Own contribution}

The mechanical experiments have been done at Linköping University by Lic. Eng. Frans Palmert and Prof. Johan Moverare and at the Metcut Research facilities in Cincinnati, Ohio, USA. The test evaluations have been done by Frans Palmert and myself and all the modelling has been done by me. Microscopy and test related images have been done by Frans Palmert and Rodger Romero Ramirez. Furthermore, the major part of the writing, in the above Papers I - VII, has been performed by me. In Paper VIII, I was responsible for the evaluations of the anisotropic stress intensity factor solutions and the corresponding writing. For the work presented in this dissertation, I am to hold the primary responsibility. 


\section{Contents}

Preface $\quad$ iii

Abstract $\quad$ vii

Zusammenfassung ix

Sammanfattning $\quad x i$

List of papers $\quad$ xiii

$\begin{array}{ll}\text { Contents } & \text { Xv }\end{array}$

$\begin{array}{ll}\text { Acronyms } & \text { xvii }\end{array}$

Part I - Background and Theory 1

1 Introduction $\quad 3$

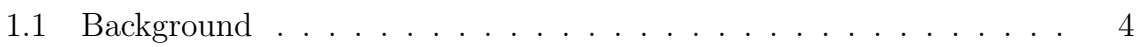

1.2 Aim of the work . . . . . . . . . . . . . 5

1.3 Outline .......................... 5

2 Gas Turbines $\quad 7$

2.1 General description . . . . . . . . . . . . . . . . . . . 8

2.2 Single-crystal nickel-base superalloys in gas turbines and relevant loading conditions . . . . . . . . . . . . . . . . . . 10

3 Nickel-Base Superalloys 13

3.1 General description . . . . . . . . . . . . . . . . . . . . . 14

3.2 Single-crystal nickel-base superalloys . . . . . . . . . . . . . . . . . 14

3.3 Characteristic fracture behaviour of single-crystals . . . . . . . . . . 16

4 Testing $\quad 19$

4.1 General overview . . . . . . . . . . . . . . . . . 20

4.2 Determination of the crystallographic orientations . . . . . . . . . 21

4.3 Fracture surfaces . . . . . . . . . . . . . . . . . 23

4.4 Heat tints . . . . . . . . . . . . . . . . . 25 
5 Fatigue Crack Growth $\quad 27$

5.1 General description . . . . . . . . . . . . . . . . . . . . 28

5.2 Fatigue crack growth modelling basis . . . . . . . . . . . . . . . . 28

5.3 Stress intensity factor and M-Integral . . . . . . . . . . . . . . . 30

6 Crystallographic Crack Growth Model 33

6.1 Crystallographic crack growth . . . . . . . . . . . . . . . . 34

6.2 Crystallographic crack driving force . . . . . . . . . . . . . . . . . . 34

6.3 Crack path prediction . . . . . . . . . . . . . . 36

6.4 Crystallographic crack growth modelling . . . . . . . . . . . . . 37

6.5 Finite element-context . . . . . . . . . . . . . . . . . . . . 40

6.6 Handling inelasticity . . . . . . . . . . . . . . . . 40

7 Review of Appended Papers $\quad 43$

8 Conclusions and Outlook $\quad 47$

8.1 Conclusions . . . . . . . . . . . . . . . . . . . . . . . . . 48

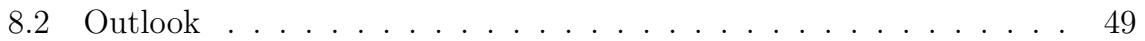

$\begin{array}{ll}\text { References } & 51\end{array}$

$\begin{array}{ll}\text { Part II - Appended Papers } & 57\end{array}$

Paper I: A finite element study of the effect of crystal orientation and misalignment on the crack driving force in a single-crystal superalloy 61

Paper II: Prediction of crystallographic cracking planes in a single-crystal nickel-base superalloy . . . . . . . . . . . . . . . . 77

Paper III: Evaluation of the crystallographic fatigue crack growth rate in a single-crystal nickel-base superalloy . . . . . . . . . . . . . 109

Paper IV: Criteria evaluation for the transition of cracking modes in a single-crystal nickel-base superalloy . . . . . . . . . . . . . . . . . . 129

Paper V: Challenges in crack propagation prediction in single-crystal nickel-base superalloys . . . . . . . . . . . . . . . . . . . 151

Paper VI: Three-dimensional LEFM prediction of fatigue crack propagation in a gas turbine disc material at component near conditions . . 169 


\section{Acronyms}

$\begin{array}{ll}\text { CDF } & \text { Crack Driving Force } \\ \text { DCT } & \text { Disc-shaped Compact Tension } \\ \text { DS } & \text { Directionally Solidified } \\ \text { EDM } & \text { Electro Discharge Machining } \\ \text { FCC } & \text { Face-Centered-Cubic } \\ \text { FCGR } & \text { Fatigue Crack Growth Rate } \\ \text { FE } & \text { Finite Element } \\ \text { HCF } & \text { High-Cycle Fatigue } \\ \text { LCF } & \text { Low-Cycle Fatigue } \\ \text { PD } & \text { Potential Drop } \\ \text { RNS } & \text { Resolved Normal Stress } \\ \text { RNSIF } & \text { Resolved Normal Stress Intensity Factor } \\ \text { RSIF } & \text { Resolved Stress Intensity Factor } \\ \text { RSS } & \text { Resolved Shear Stress } \\ \text { RSSIF } & \text { Resolved Shear Stress Intensity Factor } \\ \text { SEM } & \text { Scanning Electron Microscope } \\ \text { SIF } & \text { Stress Intensity Factor } \\ \text { TMF } & \text { ThermoMechanical Fatigue }\end{array}$





\section{Part I}

\section{Background and Theory}





\section{Introduction}

This chapter gives a context of where this research project has its place in today's world and explains its relevance for the industry and society. Further, the aims of this work are defined and the outline of this dissertation is explained. 


\subsection{Background}

The modern society consumes more energy than ever before [1], and it is estimated that the total world energy consumption will increase by $45 \%$ from 2017 to 2040 [2]. In order to counteract global warming and excessive pollution a greater share of the energy must come from green sources. Thus, in the current energy market more and more attention is given to renewable energy sources, like hydro, wind and solar power. It seems almost inevitable that renewable energies will dominate the energy market of the future. The current problem with these inherently intermittent energy sources is that it is difficult to store the generated energy efficiently and use it during the time when energy cannot be produced, e.g. when the wind is not blowing or the sun is not shining. An overproduction of energy can, for instance, be stored as hydrogen, which is a potential fuel for stationary industrial gas turbines. An industrial gas turbine can thus act as a good solution as an energy producer due its fuel flexibility and its fast start-up and shut-down times when there is a need for energy that can be dispatched at the request of the power grid operator [2]. However, most land-based gas turbines have traditionally been designed for base load operation and might undergo significant damage due to the change towards more cyclic loading conditions. Hence, a need for estimating the damage and designing the gas turbine for increased cyclic loading conditions is vital for the future energy demands.

An increase of the firing temperature raises the energy output and a higher thermal efficiency can be achieved. It is also associated with a lower fuel consumption which in turn leads to lower costs and reduced pollution [3]. Thus, the development always strives towards rising operating temperatures [4], leading to increasing requirements of the used materials to resist the high temperatures. Of all the regions in a gas turbine, the blades of the first turbine stage are the components that have to withstand the highest temperatures where also high mechanical loads are present. These components are often cast from nickel-base superalloys in the form of single-crystals. The material anisotropy coupled with the strong influence of the crystallographic orientation on single-crystal materials adds an extra dimension of complexity to the modelling, testing and understanding of the fracture mechanisms [5-13], compared to their polycrystalline counterparts.

The service life of many hot components is not only restricted by the number of cycles to crack initiation. The time spent during uncompromising crack propagation adds extra service life until the component has to be retired and replaced. Especially close to stress concentrations, one has to rely on stable and predictable crack propagation. Such damage tolerant approaches demand accurate predictions of the crack growth. This is especially difficult in single-crystal nickel-base superalloys as a crack can grow in one of two distinct cracking modes, i.e. in the direction perpendicular to the maximum tensile stress in a Mode I fashion or on a crystallographic plane [14-19]. As crystallographic crack growth is associated with an increased Fatigue Crack Growth Rate (FCGR) it is of major importance to be able to predict when the cracking mode transition occurs, on which crystallographic plane the crack grows and how fast it then propagates. Advances in the understanding of 
the fracture behaviour of single-crystal nickel-base superalloys give possibilities to achieve an increased life span, a reduction of conservatism in the design and therefore a prolongation of service intervals, the ability to support a wider fuel flexibility as well as an improvement of the capacity for cyclic operation of the next generation of advanced gas turbines for energy production.

\subsection{Aim of the work}

The aims of this project are to improve the understanding of the fatigue crack growth behaviour in single-crystal nickel-base superalloys and to develop a methodology for the prediction of the crack growth. The focus of the presented work lies on the crystallographic crack growth modelling under Low-Cycle Fatigue (LCF) conditions at $500^{\circ} \mathrm{C}$ as it corresponds to the temperature at the blade fir tree root which is a critical location in the blade design. Finite Element (FE) analyses were used to simulate the material response under the corresponding conditions and to evaluate parameters for the proposed methodology. The following research topics were of major importance:

1. How does the crystallographic orientation influence the crack growth behaviour?

2. What is an appropriate Crack Driving Force (CDF) parameter to be used in the context of crystallographic crack growth?

3. What is a suitable criterion indicating the transition of cracking mode, from growth perpendicular to the loading direction (Mode I) to cracking along the crystallographic slip planes?

4. How to predict the correct active crystallographic plane after the cracking mode transition?

5. What is the crystallographic FCGR?

6. How to incorporate inelastic effects in the otherwise linear-elastic modelling framework?

In summary, to describe the fatigue crack growth behaviour in single-crystal nickel-base superalloys the overall goal of the desired model is to predict when the transition of cracking modes occurs, to which slip plane the crystallographic crack will transition to and how fast the crystallographic crack will grow, i.e. the crystallographic FCGR.

\subsection{Outline}

Part I of the thesis gives an introduction to gas turbines and briefly discussing their basic working principle. The, for this thesis, relevant material properties of nickel-base superalloys are presented with an emphasis on single-crystals. Further, a 
discussion of the performed experiments within this project is given and important aspects, as e.g. the determination of the crystallographic orientation of the material, are covered in more detail. Moreover, the relevant background of fracture mechanics and fatigue as well as crack growth modelling in these materials is presented. In addition, the main results, conclusions and the contributions to the research society and industry are presented, where also the projects relevance from an industrial perspective is discussed. Finally, a brief review of the appended papers is given followed by an outlook on future work. This thesis builds upon the licentiate thesis Aspects of Crack Growth in Single-Crystal Nickel-base Superalloys [20] presented in December 2017. The licentiate thesis has been extended by new work, which is presented herein.

Part II contains the papers produced in this project. Paper I discusses the influence of the crystallographic orientation on the Stress Intensity Factor (SIF) indicating the effect on the crack growth behaviour. In Paper II a CDF parameter suitable for crystallographic crack growth has been developed and also a method to predict the active crystallographic plane after cracking mode transition is presented. After the crack has transitioned to a crystallographic plane it is important to be able to characterize the FCGR for crystallographic crack growth. A method to enable the evaluation of the crystallographic FCGR as well as a calibrated crack growth model has been developed in Paper III. In Paper IV criteria to predict the transition of cracking modes have been discussed and summarized into a conservative approach to indicate the risk for crystallographic crack growth. Paper V gives a brief overview of some of the challenges that were faced in this project and also by other researchers dealing with the complex subject of crack propagation prediction in single-crystal nickel-base superalloys. Finally, Paper VI gives a potential framework of how to account for inelastic effects in the linear-elastic modelling approach presented in this thesis. 


\section{Gas Turbines}

This chapter gives a brief introduction to the structure and the basic working principles of gas turbines. Further, the field of application for single-crystal materials in gas turbines and the relevant loading conditions are explained. 


\subsection{General description}

Gas turbines are mainly used in two fields; in the aviation industry acting as aircraft engines and for power generation in the energy sector. This work focuses on the stationary industrial gas turbines used for power generation, $c f$. Fig. 1. However, the basic working principles apply to both kinds of gas turbines. The main differences are the loading conditions and the heavier construction of the stationary gas turbines compared to their aeronautical counterparts. Aeronautical gas turbines usually only work at their peak load during the starting phase of a flight whereas the stationary gas turbine can work under peak load almost throughout the whole operating time to be more efficient in the power generating process. Often, stationary gas turbines are set up together with a steam turbine in a so called combined cycle power plant. There, the hot fluid leaving the gas turbine is used in the steam turbine to increase the overall efficiency.

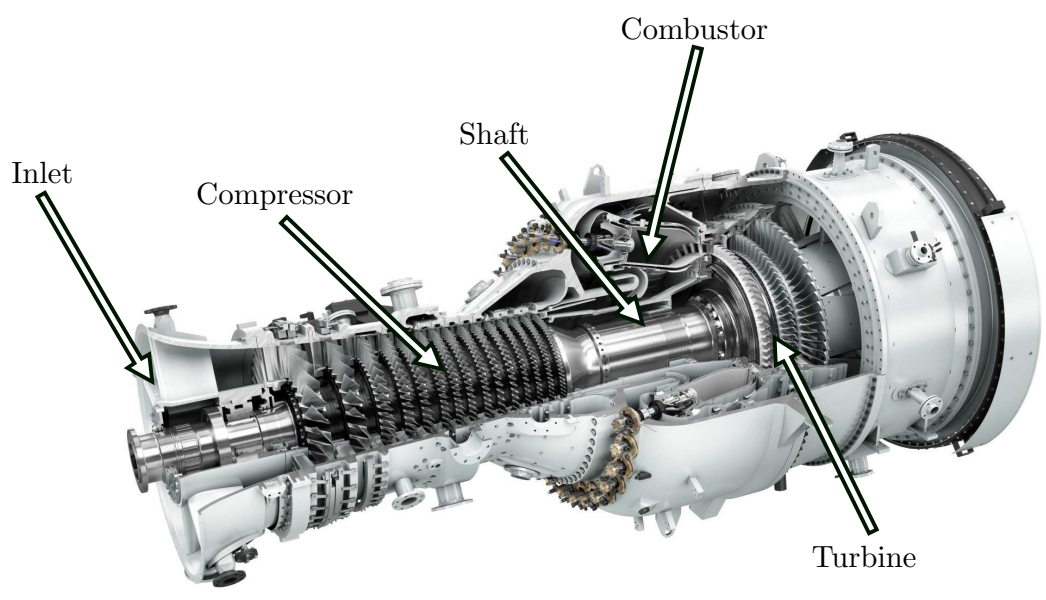

Figure 1: SGT-800 gas turbine. Courtesy of Siemens Industrial Turbomachinery AB.

Generally, the basic working principle of a stationary gas turbine for power generation can be divided into the following steps in terms of its components, $c f$. Fig. 1:

1. Inlet: Fluid passes though the inlet in the machine.

2. Compressor: The fluid undergoes a gradual compression when passing through the compressor stages and its temperature increases.

3. Combustor: Part of the hot fluid is mixed with the fuel and ignited in the combustion chamber. 
4. Turbine: A sudden expansion of the ignited fluid increases the mass flow and when the fluid hits the turbine blades, the thermal energy is converted into mechanical energy that results in the rotation of the shaft.

5. Shaft: The rotating shaft drives the compressor and is also coupled with a generator that converts the rotational energy into electrical energy.

In an ideal gas turbine there are four thermodynamic processes that the gases undergo; an isentropic compression, an isobaric combustion, an isentropic expansion and isobaric heat rejection. These processes form the so called Brayton cycle [21]. In reality, there are also some losses involved due to e.g. friction, leakage and turbulence.

The approximate gas temperature along the gas turbine is given in Fig. 2. It can be seen that the highest temperatures are present in the combustion chamber, but the turbine blades in the first turbine stage are in the most crucial environment. This is because these blade are also exposed to high mechanical loads due to centrifugal forces and high thermal gradients due to the intricate cooling system required in the blades to resist the high temperature.

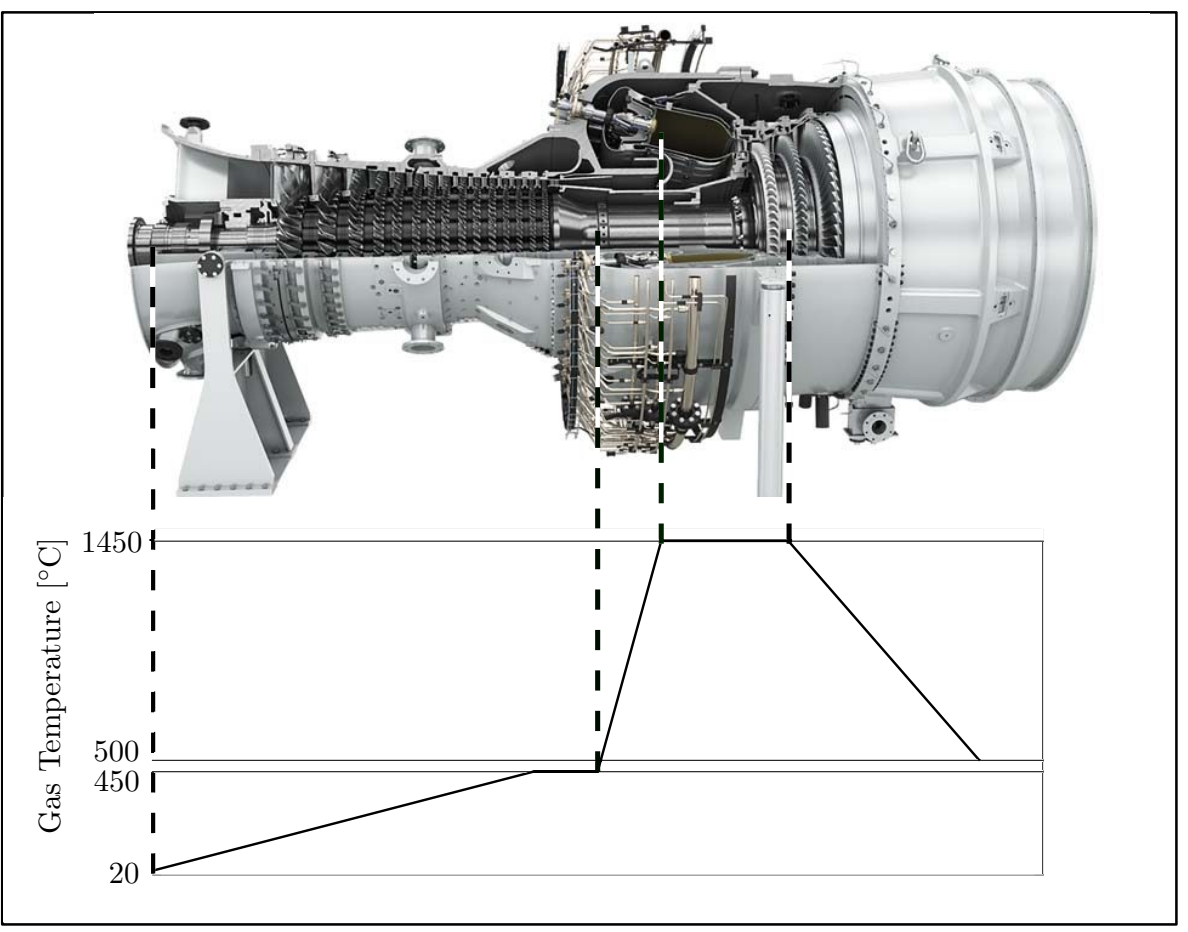

Figure 2: Gas temperature along a stationary gas turbine for power production (SGT-800). Courtesy of Siemens Industrial Turbomachinery AB. 


\subsection{Single-crystal nickel-base superalloys in gas turbines and relevant loading conditions}

In order to withstand the harsh environment in the first turbine stage with extreme temperatures, large thermal gradients and high mechanical loads, the blades are often cast from nickel-base superalloys in single-crystal form, which excel at these conditions compared to other conventional materials. They are also often the preferred choice of material for the blades of the second stage in the turbine section.

Turbine blades are generally cast with the $\langle 001\rangle$ direction (Miller notation) aligned with the length direction of the blade, as the preferred growth direction during the casting process of Face-Centered-Cubic (FCC) alloys, such as nickel, is $\langle 001\rangle$. Thus, the casting process becomes simpler and more cost efficient [22]. Further, the high temperature gradients impose strain controlled conditions on the material and thus, for a given strain, the corresponding stress is lowest for loadings in the $\langle 001\rangle$ direction and highest in the $\langle 111\rangle$ direction. This is illustrated in the schematic example of the stress-strain behaviour for different loading directions in the linear elastic region in Fig. 3. The elastic modulus in the $\langle 001\rangle$ direction is often less than half compared to the $\langle 111\rangle$ direction [23]. Consequently, the $\langle 001\rangle$ direction is the preferred choice as the casting direction for this application since it is more cost efficient and the lower elastic modulus also decreases the local plastic deformation which is associated with crack initiation and thus fatigue damage.

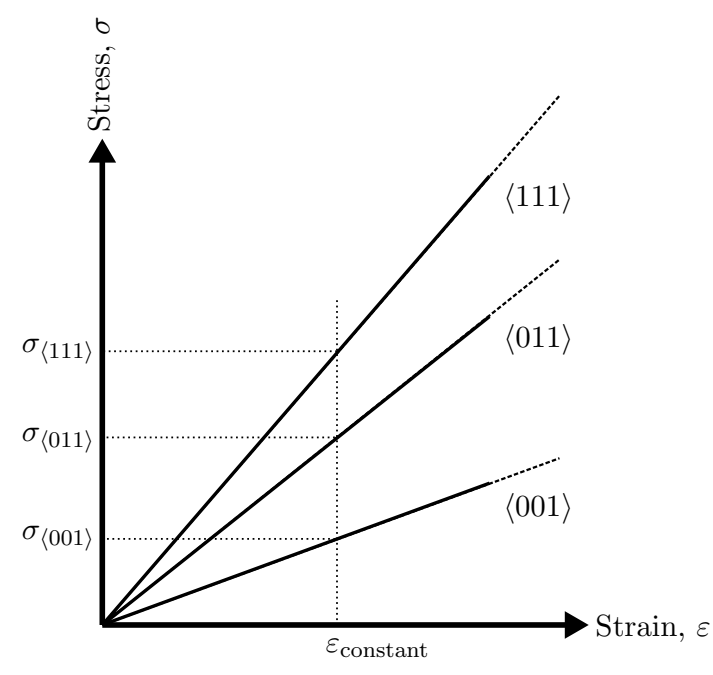

Figure 3: Schematic example of the stress-strain behaviour for different loading directions in the linear elastic region for single-crystal nickel-base superalloys. 
As explained above, the temperature in a gas turbine plays a vital role as it is associated with the power output and the efficiency, and it is thus desired to be as high as possible with respect to the material capacity.

An example of the metal temperature distribution in a turbine blade from the first stage is depicted in Fig. 4, where it can be seen that the temperature ranges from around $500^{\circ} \mathrm{C}$ at the blade foot to approximately $1000^{\circ} \mathrm{C}$ at the tip. As the temperature rarely exceeds $500^{\circ} \mathrm{C}$ at the foot, the microstructure in this area will be fairly stable and does generally not affect the material behaviour. Thus, LCF conditions can be approximated to be present in this area of the blade even though, in reality, the blade is exposed to ThermoMechanical Fatigue (TMF) conditions. This approximation simplifies the testing and evaluation, and thus the assessment of the crack initiation and growth behaviour significantly due to the simpler nature of LCF compared to TMF. A more detailed explanation of LCF and TMF will be given below.

Furthermore, in order to withstand the extreme temperatures the blades are usually coated by a thermally insulating ceramic material called Thermal Barrier Coating [24]. However, in this work focus is placed on the base material.

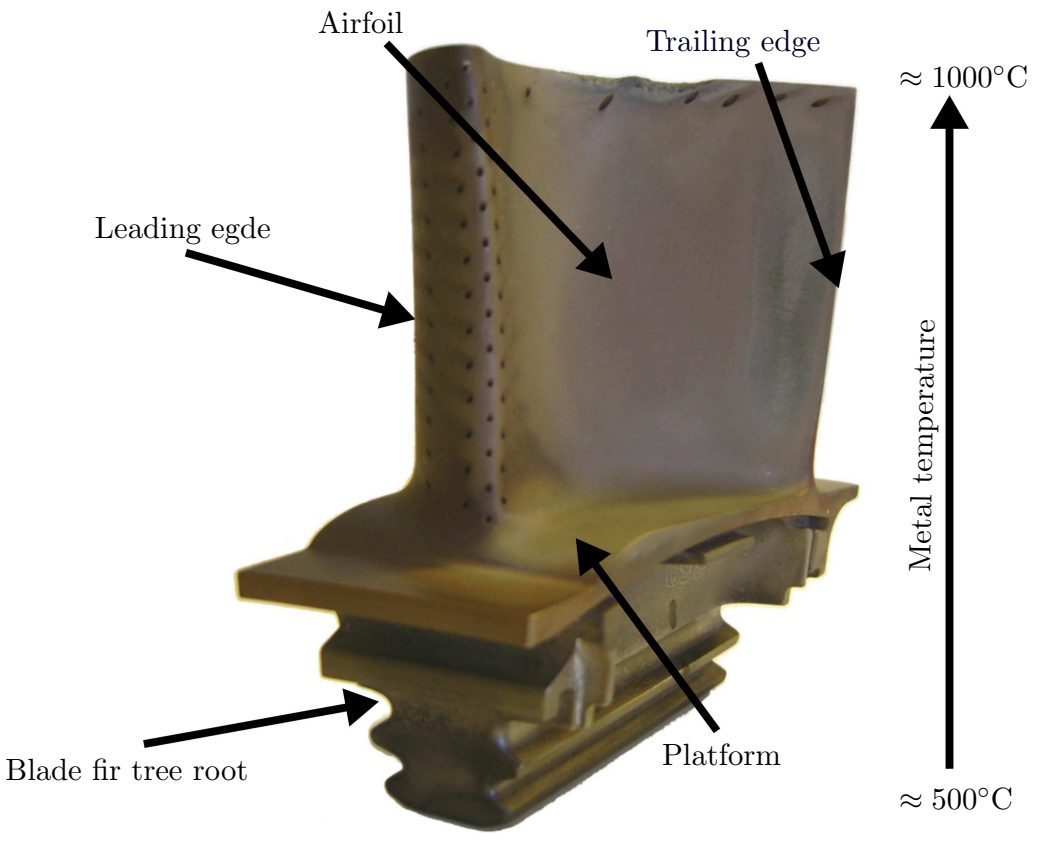

Figure 4: Metal temperature distribution in a blade in the first turbine stage. Courtesy of Siemens Industrial Turbomachinery AB. 



\section{Nickel-Base Superalloys}

This chapter introduces the material class of nickel-base superalloys and explains their relevant properties for this project. A closer look is taken at the single-crystalline form of these materials and its special properties are discussed. Further, a brief discussion of the fracture behaviour and some underlying mechanisms are given. 


\subsection{General description}

Nickel-base superalloys are often found in critical components of gas turbines due to their superior mechanical strength and creep resistance at elevated temperatures. They are used in components in the hottest sections exposed to the highest loads, since they show great resistance to mechanical and chemical degradation at temperatures close to their melting point [4]. Nickel-base superalloys can be used in three different forms; polycrystalline, Directionally Solidified (DS) and single-crystalline. Turbine disc alloys are often wrought in polycrystalline form, whereas blades are frequently cast as DS or as single-crystals. When cast as DS, the grains resemble a columnar structure with their long side in the vertical direction of the blade, as opposed to a single-crystal which consists only of one grain.

Nickel-base superalloys usually contain several different alloying elements, where the base is nickel. This is due to the FCC crystal structure of nickel, which makes it tough and ductile and also stable so that no phase transformation occurs during a temperature increase from room temperature until its melting point. As an example, some of the possible alloying elements, besides nickel, are listed in Table 1 together with their corresponding function in the alloy $[22,25,26]$.

The material properties of the superalloys are, as stated earlier, mainly governed by the microstructure and its phase composition. The most common phases are $\gamma$ and $\gamma^{\prime}$. The $\gamma$-phase is the matrix and has FCC structure due to the fact that the nickel resides there. The $\gamma^{\prime}$-phase is the principal strengthening phase [27] in turbine single-crystal materials and also of FCC structure. The $\gamma / \gamma^{\prime}$-phase composition is shown in the Scanning Electron Microscope (SEM) pictures in Fig. 5 at four different magnifications, where the darker matrix phase is $\gamma$ and the brighter phase is $\gamma^{\prime}$. Note that Fig. 5 depicts a single-crystal, but the same microstructure is present in each grain when cast in polycrystalline or DS form.

\subsection{Single-crystal nickel-base superalloys}

All turbine blades are generally cast due to their complex structure involving cooling channels. As mentioned above, nickel-base superalloys can be cast in monocrystalline form, i.e. as single-crystals, by the complicated process of investment casting with

Table 1: Example of some alloying element in nickel-base superalloys with their corresponding function.

\begin{tabular}{ll} 
Alloying element & Function \\
\hline Aluminium & strength, oxidation and corrosion resistance \\
Cobalt & improving creep properties, oxidation and corrosion resistance \\
Chromium & improving creep properties, oxidation and corrosion resistance \\
Molybdenum & strengthening of $\gamma$-phase \\
Rhenium & strengthening of $\gamma$-phase, improving creep properties \\
Tungsten & strengthening of $\gamma$-phase, improving creep properties \\
Tantalum & strength, improving creep properties \\
\hline
\end{tabular}



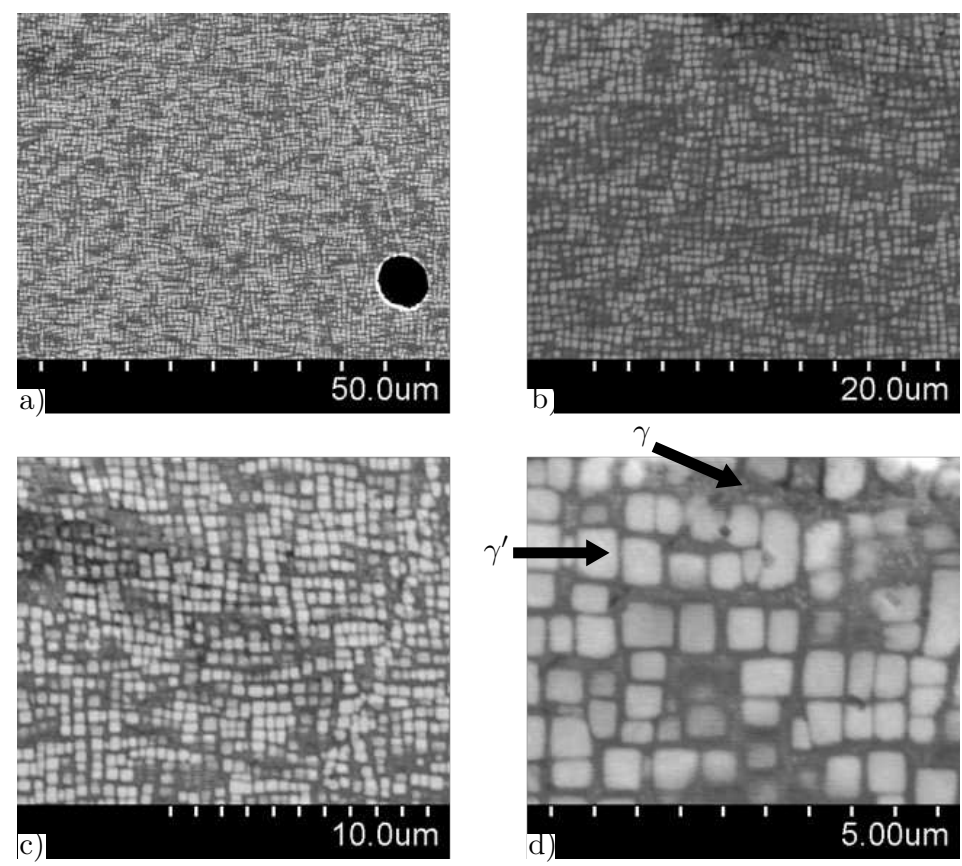

Figure 5: Illustration of the microstructure with the $\gamma$ - and $\gamma^{\prime}$-structure at an increasing magnification from a) to d) in a single-crystal superalloy.

directional solidification. Here only one grain is allowed to grow into the casting form during the casting process and thus eliminating the grain boundaries leading to improved creep properties compared to polycrystalline nickel-base superalloys. The absence of grain boundaries also results in an anisotropic material behaviour. In case of single-crystal nickel-base superalloys a cubic anisotropy is present. Inelastic deformations occur along the so called close-packed planes or discrete slip planes. In materials with FCC crystal lattice structure there are four $\{111\}$ slip planes. On each slip plane there exist three primary slip directions of $\langle 011\rangle$-type, which results in twelve primary slip systems, $c f$. Table 2 .

These materials exhibit not only elastic but also plastic anisotropy as well as tension and compression asymmetry. In addition, the hardening behaviour can be approximated to be perfectly-plastic [5]. The single-crystal nickel-base superalloy that was considered in this work is similar to one presented by Reed et al. [22]. It shows strength and other properties comparable to available commercial single-

Table 2: Definition of the primary slip systems $\alpha$ with corresponding slip plane normal $\boldsymbol{n}^{\alpha}$ and direction $\boldsymbol{b}^{\alpha}$.

\begin{tabular}{c||c|c|c|c|c|c|c|c|c|c|c|c}
\hline$\alpha$ & 1 & 2 & 3 & 4 & 5 & 6 & 7 & 8 & 9 & 10 & 11 & 12 \\
$\boldsymbol{n}^{\alpha}$ & $(11 \overline{1})$ & $(111)$ & $(11 \overline{1})$ & $(1 \overline{1} \overline{1})$ & $(\overline{1} \overline{1} \overline{1})$ & $(1 \overline{1} \overline{1})$ & $(\overline{1} 1 \overline{1})$ & $(\overline{1} 1 \overline{1})$ & $(\overline{1} 1 \overline{1})$ & $(\overline{1} \overline{1} 1)$ & $(\overline{1} \overline{1} 1)$ & $(\overline{1} \overline{1} 1)$ \\
$\boldsymbol{b}^{\alpha}$ & {$[01 \overline{1}]$} & {$[\overline{1} 01]$} & {$[1 \overline{1} 0]$} & {$[0 \overline{1} 1]$} & {$[\overline{1} 0 \overline{1}]$} & {$[110]$} & {$[011]$} & {$[10 \overline{1}]$} & {$[\overline{1} \overline{1} 0]$} & {$[0 \overline{1} \overline{1}]$} & {$[101]$} & {$[\overline{1} 10]$} \\
\hline
\end{tabular}


crystal materials used for similar applications, but with improved oxidation and corrosion resistance [28].

One particular aspect complicating the understanding of the behaviour of singlecrystal materials is the dependency on the crystallographic orientation, which influences the stress state and thus the fracture behaviour [19, 29]. Hence, the material response is strongly coupled to the crystallographic orientation [17, 29-34] and it is thus crucial to be able to accurately determine it. Often only the primary orientation is accounted for during the casting procedure, while the secondary orientation is not determined. This uncertainty will most probably lead to an imprecise prediction of the material response.

As the matrix is of FCC structure, with residing $\gamma^{\prime}$-particles acting as precipitation strengtheners, the dislocation movement on the crystallographic $\{111\}$-planes is the predominant slip mode, where the inelastic deformation may eventually cause damage accumulation leading to crack initiation and subsequent crack growth.

\subsection{Characteristic fracture behaviour of single-crystals}

Cracks in this class of materials generally grow in one of two distinct cracking modes. The crack either grows in a Mode I fashion perpendicular to the maximum tensile stress or on the crystallographic slip planes. It has frequently been shown that the crack transitions from one cracking mode to the other, i.e. from Mode I to crystallographic cracking, cf. Fig. 6, or vice versa. In this work microscopic local crack growth on conjugate slip planes in a zigzag fashion is disregarded and thus a transition of cracking modes is considered to have occurred only when a stable crystallographic crack continued to grow in a dominant fashion and is not taken over by Mode I crack growth. The crystallographic FCGR has been shown

DCT

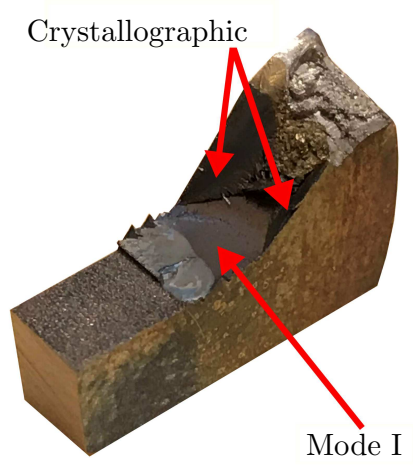

$\mathrm{Kb}$

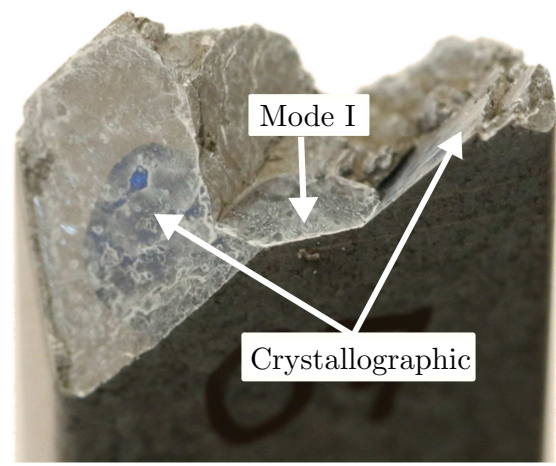

Figure 6: Illustration of the transition from one distinct cracking mode to another for the DCT (left) and Kb (right) specimen geometry. 
to be higher compared to Mode I $[35,36]$. In most of the published literature it can be seen that the propensity for a transition from Mode I to crystallographic crack growth decreases with increasing temperature. This was explained by the fact that the shear strength of the $\gamma^{\prime}$, which are sheared during crystallographic crack growth, increases with rising temperatures. A study by Palmert et al. [37] on the alloy examined in this work showed that it exhibits the highest propensity for crystallographic crack growth at $500^{\circ} \mathrm{C}$ rather than at higher or lower temperatures. The nature of this phenomenon is still under investigation.

Antolovich et al. [38] argued that there exist two dominant cracking modes in a single-crystal nickel-base superalloy. The first is associated with crystallographic cracking on the octahedral $\{111\}$-planes, which is governed by shearing the $\gamma^{\prime}$ particles. The other represents the macroscopic Mode I crack growth where, locally, the crack grows on a combination of $\{111\}$ - and $\{100\}$-planes. Here, the crack grows on the octahedral planes avoiding the shearing of the $\gamma^{\prime}$-particles, and at the $\gamma^{\prime} / \gamma$-interface on the $\{100\}$-planes. In this project a similar behaviour was observed where the $\gamma^{\prime}$-particles where either sheared for crystallographic crack growth or avoided during macroscopic Mode I crack growth. This is illustrated in Fig. 7, where a shearing of the $\gamma^{\prime}$-particles can be observed for crystallographic cracking at the top and the avoidance for a Mode I crack at the bottom.
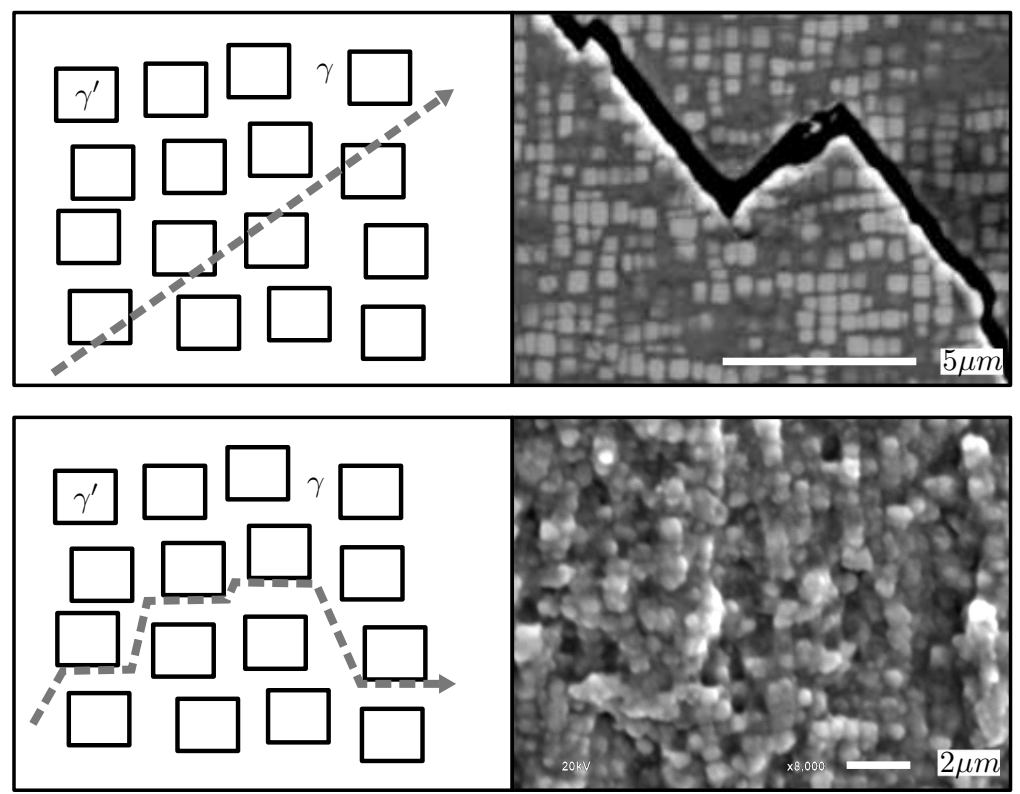

Figure 7: Illustration of the two proposed cracking modes in a singlecrystal nickel-base superalloy with the shearing (top) and the avoidance (bottom) of the $\gamma^{\prime}$-particles. Note that the avoidance is depicted from a top view onto a Mode I fracture surface. 



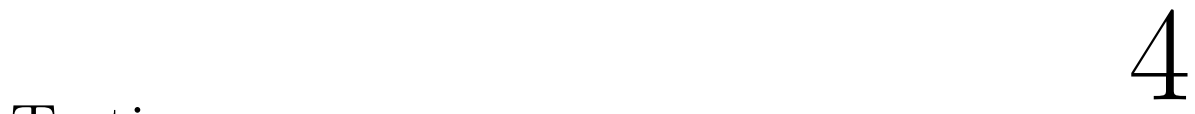

Testing

This chapter presents the testing that has been conducted within this research project. The data produced in the experiments were used to develop, calibrate and validate the proposed models. The focus of this chapter lies on the determination of the crystallographic orientation and the examination of the fracture surfaces with visible heat tints. More details of the testing procedure are given in Paper II. 


\subsection{General overview}

In order to gain a better understanding of the material and crack growth behaviour of single-crystal nickel-base superalloys in service, experiments which are relevant in comparison to the conditions of the real component are vital.

As $500^{\circ} \mathrm{C}$ is a relevant temperature for the blade foot, $c f$. Fig. 4, it was taken to be in the focus of the testing and modelling work in this project. As explained above, the microstructure and thus the material properties are fairly stable up to a temperature of $500^{\circ} \mathrm{C}$. Thus, LCF testing with a temperature of $500^{\circ} \mathrm{C}$ has been performed in this project as it can be used to describe the component behaviour in that area of the blade to a satisfactory degree.

In this project, 16 force controlled experiments on two different specimen geometries were performed and evaluated; six surface flawed fatigue crack growth specimens of Kb-type [39] and ten Disc-shaped Compact Tension (DCT) specimens. In all experiments, a flaw was introduced by Electro Discharge Machining (EDM) and the crack growth was initiated by a precracking block. The technical drawings of the specimens are shown in Fig. 8, where also the nominal primary directions are highlighted. Note that the machined surface flaw of the Kb specimens is centred at the flat surface with the normal [100]. All Kb specimens were tested with the primary direction of [001] as shown in Fig. 8, whereas the loading direction was altered for five of the DCT specimens; three were loaded in [120] and two in [110] as the crystal was rotated about the nominal [001] direction. Among these experiments, three different loading frequencies, i.e. $f=0.5 \mathrm{~Hz}, f=0.1 \mathrm{~Hz}$ and $f=0.025 \mathrm{~Hz}$, and several different applied force levels were tested. The loading ratios were 0.05 and 0.1 for the Kb and DCT experiments, respectively. The tests were performed according to the standard ASTM E647 [40]. In general, the fatigue crack growth testing of single-crystal nickel-base superalloy specimens has been proven to be

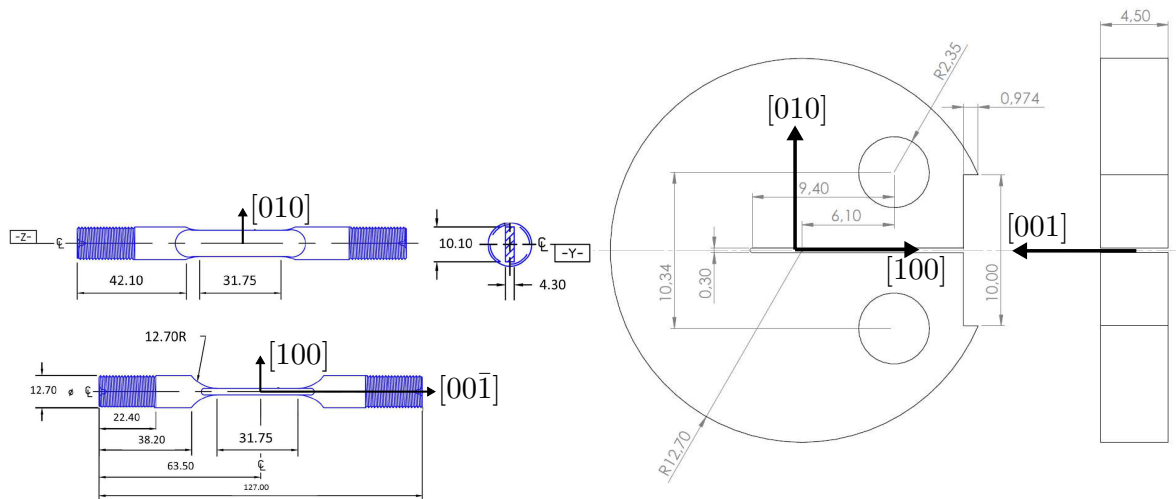

Figure 8: Technical drawing of the Kb specimen (left) and the DCT specimen (right) with dimensions in $\mathrm{mm}$ and the nominal primary and secondary orientations marked. 
highly difficult, since the tested specimens can experience uneven and unusual crack growth in an unanticipated matter. Further, as the cracks tend to switch cracking mode from cracking perpendicular to the loading direction to crystallographic cracking, an experimental evaluation of the FCGR is complicated.

The crack lengths in the performed experiments were approximated by direct current Potential Drop (PD) measurements, where the voltage between two points, one on each side of the crack, was evaluated. The potential drop measurements were used to derive the cracked area during the experiment. The crack front shape must be known to correlate the test signal (cracked area) to a crack length. Thus, heat tints on the fracture surfaces were used for additional information about the crack front shapes, which were evaluated after the experiments were performed. Many heat tints are difficult or impossible to see due to the erratic crack growth. Thus, this approach can be difficult to use in some cases, especially once crystallographic cracking was present. This is further discussed below.

The main goal of the experiments was to generate LCF test data, to study the crack growth behaviour and to give a base for calibration and validation of the developed models at the temperature of $500^{\circ} \mathrm{C}$. A difficulty in this context is the determination of the FCGR associated with the crystallographic cracking mode, where crack length and cracked surface area can deviate substantially from conventional Mode I cracks.

It can be noted that the experiments on the $\mathrm{Kb}$ specimen yielded more consistent data compared to DCT specimens where more scatter was present. This might be attributed to the geometry of the DCT specimen with the load line far away from the crack initiation location possibly introducing bending and also a loading through pins that might experience friction, to mention a few possible issues.

\subsection{Determination of the crystallographic orientations}

The above discussed importance of the crystallographic orientation and its influence on the mechanical behaviour motivates an accurate determination of how the crystal is aligned in a structure. The growth direction of the crystal is difficult to control during the casting process and thus misalignments from the nominal crystallographic directions are almost impossible to eliminate. In the context of industrial components, secondary orientations are generally not accounted for in the during the casting. In order to model the correct material response, it is important to know the correct crystallographic orientation, which is generally determined for test specimens. One approach to obtain the crystallographic orientation was reported in Paper II, where the angles of visible dendrites on three polished orthogonal faces were measured and evaluated. The dendrites give the projections of the crystallographic lattice vectors on the measured planes, $c f$. Fig. 9 for an example of visible dendrites on surfaces of a DCT and a Kb specimen, respectively. The measured angles were post-processed to find the best fit of the crystallographic orientation using an optimization routine. This was done to determine an orthogonal Cartesian coordinate system since the measured angles on one surface contain a 

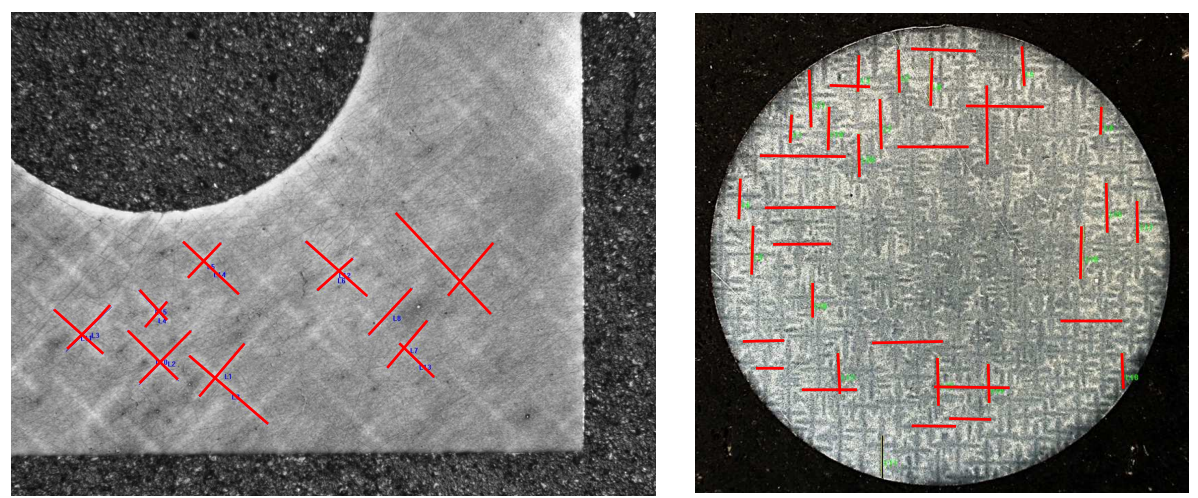

Figure 9: Illustration of surfaces of a DCT (left) and a Kb (right) specimen for the evaluation of the crystallographic orientation with some highlighted dendrites.

scatter. This can be due to the inhomogeneous solidification of the material during the manufacturing process, measurement inaccuracies or local low angle grain boundaries. For further details the reader is referred to Paper II. An example regarding the material misalignments is illustrated in Fig. 10, where the orientation of the crystal coordinate system is shown together with the reference coordinate system (nominal crystallographic orientation). The computed crystallographic orientation is then used to model the material response more accurately in the corresponding test specimen. A drawback with this procedure is that the test piece often must be cut to get the three orthogonal surfaces and will thus be destroyed. This might be suitable for test specimens in a post-experimental examination but is not applicable for components before they are used in operation.

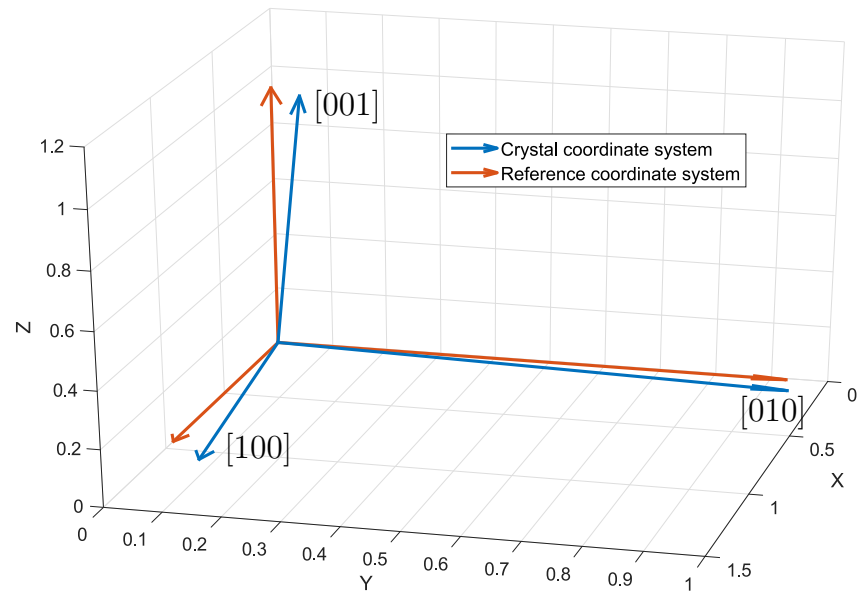

Figure 10: Representation of the crystal coordinate system [20]. 


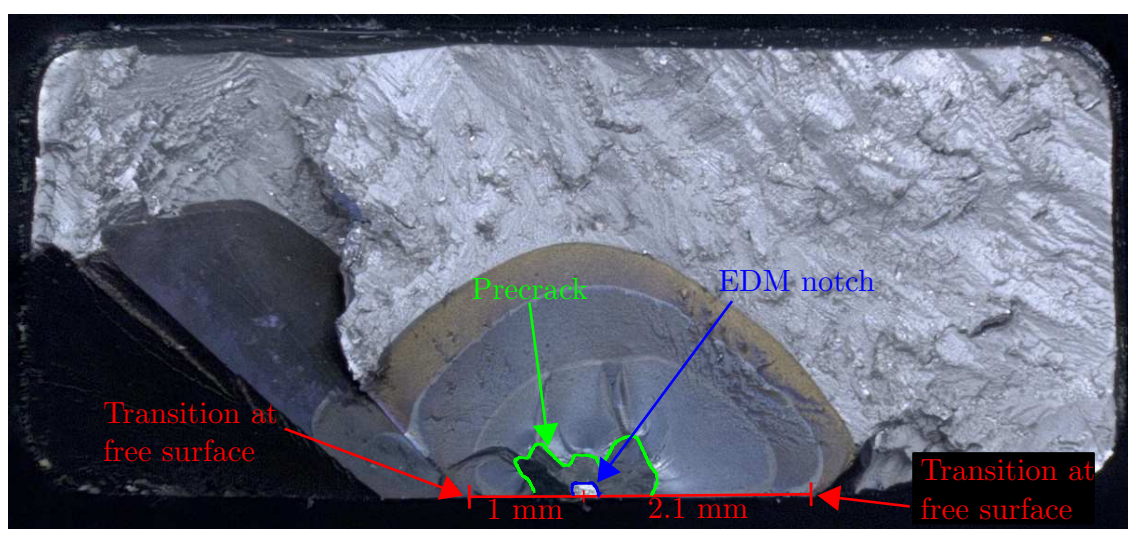

Figure 11: Illustration of the EDM notch, precrack and the transition of cracking modes at the free surfaces with corresponding crack lengths on the fracture surface of a Kb specimen.

\subsection{Fracture surfaces}

After the experiments, the fracture surfaces were analysed in order to determine the crack path, i.e. the active crystallographic cracking plane and also the instance of cracking mode transition. Furthermore, visible heat tints on the fracture surfaces were used to evaluate the FCGRs for the Mode I and the crystallographic portions of the crack. It has been shown by the experiments that the crack grew from the EDM notch in a macroscopic Mode I fashion. During the precracking, the crack could grow on conjugate slip planes, but continued in stable Mode I growth in most specimens. Eventually the crack transitioned to a crystallographic plane for further growth. This transition occurred first at the free surfaces for all considered experiments for both the $\mathrm{Kb}$ as well as the DCT specimens. This is illustrated in Fig. 11, where a fracture surface of a Kb specimen with the corresponding crack length at cracking mode transition is shown.
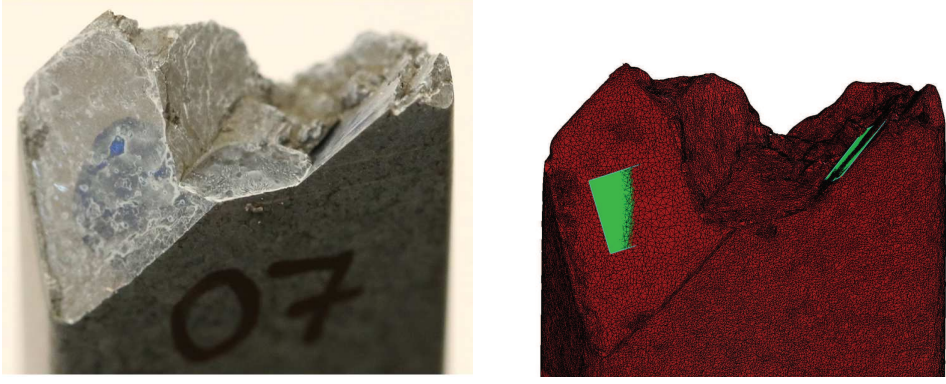

Figure 12: Fracture surface of a $\mathrm{Kb}$ specimen (left) with its 3Drepresentation (right). 


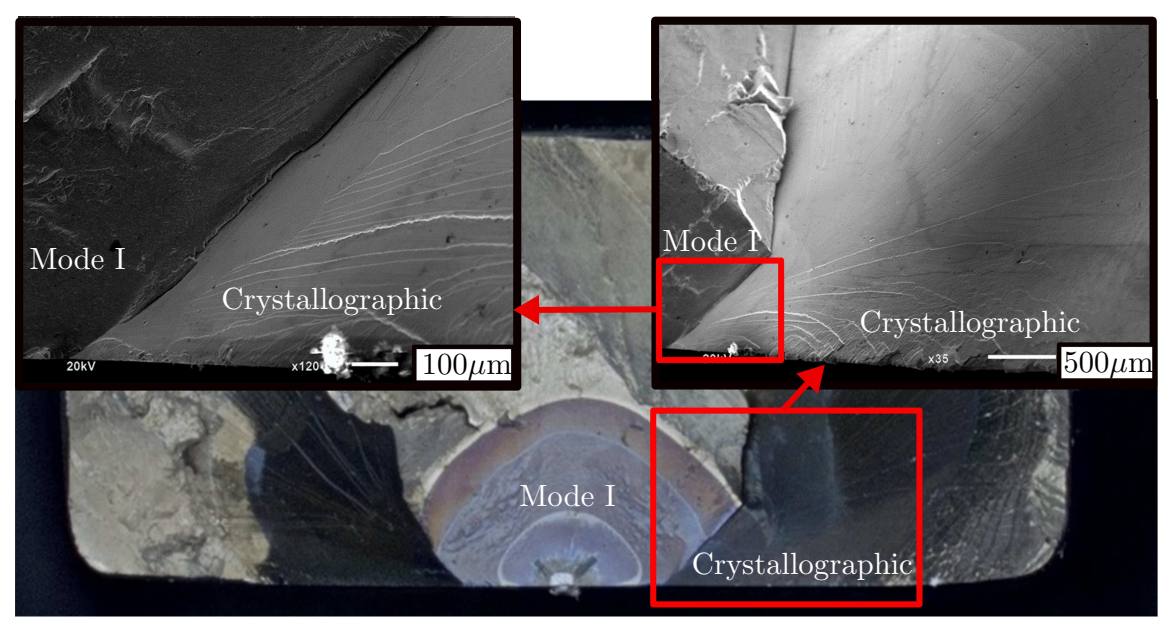

Figure 13: Fracture surface of a Kb specimen with the area of cracking mode transition magnified by SEM showing that the crystallographic crack grew beneath the Mode I crack.

Furthermore, the fracture surfaces were scanned to create a 3D-representation in terms of triangular finite elements. This facilitated the determination of the active $\{111\}$ crystallographic planes that the crack transitioned to and grew on during the tests. Further, the 3D-triangulation was used to create models of the crack geometries that were used in FE-analyses, as will be elaborated below. A post-experiment Kb specimen and the corresponding 3D-scanned fracture surface can be seen in Fig. 12, where the green planes are the two active crystallographic planes $((\overline{1} 1 \overline{1})$ and $(\overline{1} \overline{1} 1))$.

An SEM scrutinisation of the fracture surfaces revealed that the crack shapes can be very complex. An example of a Kb specimen is illustrated in Fig. 13, where it can be seen that the crystallographic cracks grew beneath the Mode I crack after the cracking mode transition.

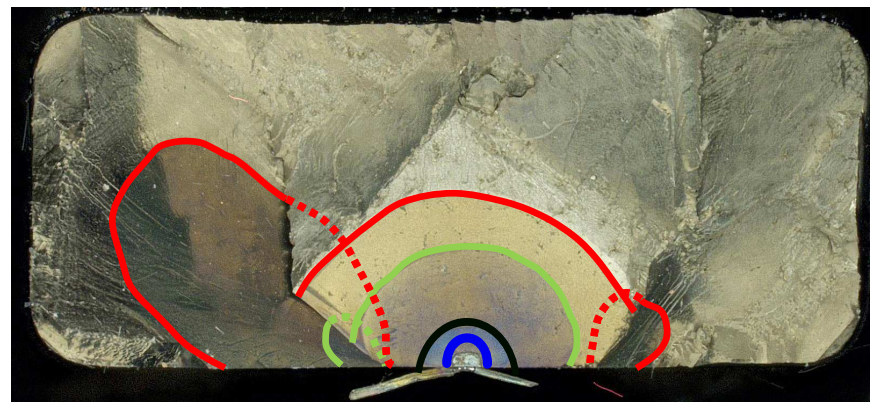

Figure 14: Depiction of a fracture surface of a Kb specimen with highlighted heat tints. 


\subsection{Heat tints}

As described above, in order to extract the crack length from the PD signal and to be able to further characterise the crack path, heat tints were applied during the experiments. They enabled the determination of the crack front shapes for the specific instances when they were applied. The heat tints were created through oxidisation on the specimen surfaces by applying a hold time at a constant load ensuring an open crack. An example of a Kb specimen with highlighted heat tints is depicted in Fig. 14. The portions of the cracks that grew beneath the Mode I crack are represented by dashed lines. It should be noted that these shapes were approximated as they are hidden. Comparing the heat tints, highlighted in green and red at both cracking modes, it can be seen that the crystallographic portion of the crack grew considerably faster than the Mode I crack. This distinct difference in the growth rate for the two cracking modes emphasizes the importance of being capable to predict the transition of cracking modes as well as the corresponding FCGRs. 



\section{Fatigue Crack Growth}

This chapter discusses the fundamentals of fatigue crack growth. The aim is to give an introduction by explaining the relevant theoretical fundamentals of conventional fatigue crack growth. 


\subsection{General description}

Often, the allowed life time of a component is restricted only to the time to crack initiation until it gets retired from service. This conservative approach can waste a substantial part of a components life. In fact, the total cyclic life of a component consists of the number of cycles until crack initiation and also number of cycles spend during uncompromising crack growth. In the case of single-crystal nickel-base superalloys it can be reasonable to divide the crack growth stage into Mode I and crystallographic crack growth since they are associated with different FCGRs. By also incorporating stable crack growth the time in operation could be increased significantly. The fatigue crack growth portion of the total cyclic life is often neglected, since it is more difficult in terms of modelling and testing. This is especially the case for anisotropic materials as single-crystal nickel-base superalloys with their complicated cracking behaviour. Crack initiation modelling is outside the scope of this work, but the interested reader is referred to e.g. [15].

Fatigue occurs at repeated cyclic loading and is commonly divided into several different categories, e.g. High-Cycle Fatigue (HCF), LCF or TMF. LCF and TMF occurs when the local stress due to mechanical loads is at or beyond the yield limit and consequently $\mathrm{HCF}$ when it is below. The temperature is assumed to be constant for LCF and HCF, whereas in TMF also the temperature is cycled with or without a phase difference to the mechanical load.

In the following, both index and symbolic notation are used for expressing tensors and for the sake of readability the more comprehensible notation is chosen for the appropriate cases. Bold characters are used for symbolic notation.

\subsection{Fatigue crack growth modelling basis}

In order to predict the cyclic life time after crack initiation in a material, a crack growth model needs to be developed. Generally, such a model is described as the cyclic crack growth rate $d a / d N$ as a function of certain parameters like CDFs, e.g. the SIF-range for the different modes of fracture $\left(\Delta K_{I}, \Delta K_{I I}, \Delta K_{I I I}\right)$, loading ratio $R$, temperature $T$ and the direction of crack growth $\boldsymbol{d}$ to mention a few:

$$
\frac{d a}{d N}=f\left(\Delta K_{I}, \Delta K_{I I}, \Delta K_{I I I}, R, T, \boldsymbol{d}, \ldots\right) .
$$

The arguments found in Eq. 1 are only some of the potential factors influencing the crack growth behaviour in single-crystal nickel-base superalloys. The most widely used model for subcritical crack growth was developed by Paris et al. [41, 42], which relates the crack growth rate to the SIF-range as follows:

$$
\frac{d a}{d N}=C(\Delta K)^{m}
$$

where $C$ and $m$ are empirical constants and $\Delta K=K_{\max }-K_{\min } . \Delta K$ may be interchanged with any other appropriate CDF parameter. The advantage with 
this model is its simplicity with only two constants that have to be determined. Elber [43] presented a modified Paris equation accounting for crack closure, where $\Delta K$ in Eq. 2 is $\Delta K_{\text {eff }}=K_{\max }-K_{\text {open }}$. Here, the effective SIF-range corresponds to the maximum $K$ minus the $K$-value at the instance when the crack closes, i.e. the crack flanks get in contact at the crack tip. The phenomenon of crack closure was not studied to any further extent in this work as it was assumed to have a negligible effect on the performed evaluations due to the above mentioned low loading ratios in the experiments. Nonetheless, the complexity of the 3D crack geometries present at crystallographic crack growth will make the evaluation of such closure levels substantially more difficult compared to ordinary Mode I cracks.

Generally, the crack growth rate is plotted in a double logarithmic diagram over the SIF-range, $c f$. Fig. 15. Most metallic materials show three distinct regions of crack growth behaviour, as seen in the plot. In region I the crack propagation rates are very low. Below the threshold value $\Delta K_{\text {th }}$ no crack growth is expected. Region II represents stable macroscopic crack growth. In region III the fatigue crack growth is considered unstable, which leads to very high crack growth rates. The critical value for this region is the fracture toughness, which at plane strain is denoted $K_{\text {Ic }}$. When $K_{\text {Ic }}$ is reached, a failure of the component is imminent. The typically linear region II in Fig. 15 can be described by Eq. 2. The most common expression to describe the fatigue crack growth in all three regions was first presented by Forman and Mettu [44]. This more detailed expression has the drawback that it contains six constants compared two in the equations presented by Paris. Considering the significantly greater complexity of testing and modelling in regions I and III and also the premise that stable fatigue crack growth occurs predominantly in region II it is concluded that Eq. 2 is a good starting point to define a crack growth model. Consequently, regions I and III were not accounted for in this work. In order to calculate the fatigue life of a component the corresponding crack growth equations can be integrated and added to the time until crack initiation to determine the total cyclic life time of a component.

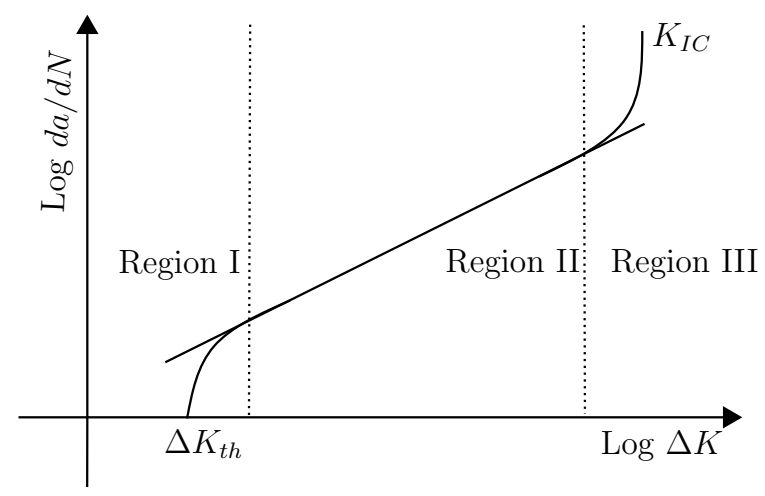

Figure 15: Fatigue crack propagation regions [20]. 


\subsection{Stress intensity factor and M-Integral}

In order to make a reliable estimation of the fatigue life using a crack growth model, an appropriate CDF parameter must be established and is therefore of high importance. A commonly used CDF is the SIF, which is a measure to describe the singular stress state at the crack tip. The conventional SIFs are categorized into $K_{I}, K_{I I}$ and $K_{I I I}$, representing the three modes of fracture, i.e. opening, in-plane shear and out-of-plane shear, respectively, and can be defined either by means of far-field stresses or local stresses around the crack tip. In terms of far field stresses the Mode I SIF can be defined as:

$$
K_{I}=\sigma_{\infty} \sqrt{\pi a} f,
$$

where $\sigma_{\infty}$ is the far-field stress, $a$ is the crack length and $f$ is a geometry function. This can only be used if the geometry function is known by e.g. handbook solutions. In terms of local stresses the SIFs are defined for $\theta=0, c f$. Fig. 16, by:

$$
\begin{aligned}
& K_{I}=\lim _{r \rightarrow 0} \sqrt{2 \pi r} \sigma_{y y} \\
& K_{I I}=\lim _{r \rightarrow 0} \sqrt{2 \pi r} \tau_{y x} \\
& K_{I I I}=\lim _{r \rightarrow 0} \sqrt{2 \pi r} \tau_{y z},
\end{aligned}
$$

where $r$ is defined on a plane perpendicular to the crack front as illustrated in Fig. 16 and $\sigma_{y y}, \tau_{y x}$ and $\tau_{y z}$ are local stresses at the distance $r$ from the crack tip [45]. The difficulty with this approach is that the local stresses have to be known and are often difficult to determine in the presence of a crack. Another approach to calculate the SIFs in linear elastic materials is by means of the energy release rate $G$ developed by Irwin [46], which relates the change of potential energy $\Pi$ to the crack area $A$ :

$$
G_{I}=\alpha K_{I}^{2}, \quad G_{I I}=\alpha K_{I I}^{2},
$$

where

$$
\alpha=\left\{\begin{array}{ccc}
\left(1-\nu^{2}\right) / E & \text { for } & \text { plane strain } \\
1 / E & \text { for } & \text { plane stress }
\end{array}\right.
$$

and where

$$
G=-\frac{d \Pi}{d A} .
$$

The M-Integral developed by Yau et al. [48] has indirectly been used throughout this work to calculate the SIFs. It was developed from the J-Integral, to extract the SIFs for the three modes of fracture. In the following, the concept is briefly explained for a 2D-formulation and isotropic material properties. The theory can then be extended into a 3D-context for generally anisotropic materials $[49,50]$. The J-Integral is given by:

$$
J=\int_{\Gamma}\left(W d y-T_{i} \frac{\partial u_{i}}{\partial x}\right) d s
$$




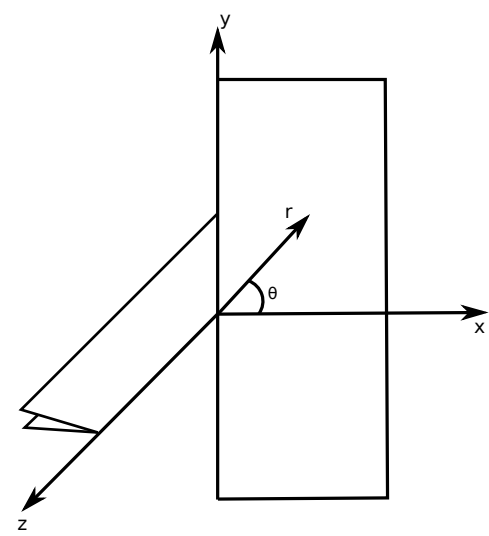

Figure 16: Crack front cartesian and cylindrical coordinate system [47].

where $W=\sigma_{i j} \varepsilon_{i j} / 2$ is the strain energy density, $T_{i}=\sigma_{i j} n_{j}$ are the components of the traction vector, $u_{i}$ are the components of the displacement vector and $i, j=1,2$. Further, $\Gamma$ is the integration path and $d s$ is a length increment along $\Gamma$ as illustrated by the arbitrary contour around the crack tip in Fig. 17 .

In the context of linear elasticity, the J-Integral is equal to the energy release rate during mixed-mode crack extension and is in $2 \mathrm{D}$ expressed as:

$$
J=G_{I}+G_{I I} .
$$

In terms of SIFs, the J-Integral can be expressed by inserting Eq. 5 into Eq. 8 as:

$$
J=\alpha\left(K_{I}^{2}+K_{I I}^{2}\right) .
$$

Using the applicability of linear superposition, two arbitrary stress states can be superimposed to get a third:

$$
K_{I}^{(0)}=K_{I}^{(1)}+K_{I}^{(2)} ; \quad K_{I I}^{(0)}=K_{I I}^{(1)}+K_{I I}^{(2)},
$$

where the state is denoted by the superscript. Applying the superposition principle from Eq. 10 to Eq. 9 gives:

$$
J^{(0)}=\alpha\left(\left[K_{I}^{(1)}+K_{I}^{(2)}\right]^{2}+\left[K_{I I}^{(1)}+K_{I I}^{(2)}\right]^{2}\right) .
$$

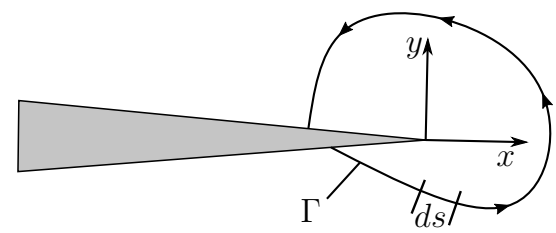

Figure 17: Arbitrary contour around the crack tip [20]. 
Expanding the terms and comparing them to Eq. 9 gives:

$$
J^{(0)}=\underbrace{\alpha\left(K_{I}^{(1)^{2}}+K_{I I}^{(1)^{2}}\right)}_{J^{(1)}}+\underbrace{\alpha\left(K_{I}^{(2)^{2}}+K_{I I}^{(2)}\right)}_{J^{(2)}}+\underbrace{2 \alpha\left(K_{I}^{(1)} K_{I}^{(2)}+K_{I I}^{(1)} K_{I I}^{(2)}\right)}_{M^{(1,2)}},
$$

where the M-Integral is the last term and is defined as:

$$
\begin{aligned}
M^{(1,2)}=2 \alpha\left(K_{I}^{(1)} K_{I}^{(2)}\right. & \left.+K_{I I}^{(1)} K_{I I}^{(2)}\right) \\
& =\int_{\Gamma}\left(W^{(1,2)} d y-\left[T_{i}^{(1)} \frac{\partial u_{i}^{(2)}}{\partial x}+T_{i}^{(2)} \frac{\partial u_{i}^{(1)}}{\partial x}\right] d s\right),
\end{aligned}
$$

where $W^{(1,2)}$ is the mutual potential energy density: $W^{(1,2)}=\sigma_{i j}^{(1)} \varepsilon_{i j}^{(2)}=\sigma_{i j}^{(2)} \varepsilon_{i j}^{(1)}$. To determine unique solutions of $K_{I}$ and $K_{I I}$ two appropriate auxiliary solutions are to be chosen as: $K_{I}^{(2 a)}=1$ and $K_{I I}^{(2 a)}=0$, and $K_{I}^{(2 b)}=0$ and $K_{I I}^{(2 b)}=1$. Using auxiliary solution $(2 a)$ Eq. 13 can be solved for $K_{I}^{(1)}$ as:

$$
K_{I}^{(1)}=\frac{1}{2 \alpha} M^{(1,2 a)}=\frac{1}{2 \alpha} \int_{\Gamma}\left(W^{(1,2 a)} d y-\left[T_{i}^{(1)} \frac{\partial u_{i}^{(2 a)}}{\partial x}+T_{i}^{(2 a)} \frac{\partial u_{i}^{(1)}}{\partial x}\right] d s\right),
$$

where $T_{i}^{(1)}$ and $u_{i}^{(1)}$ are determined from the FE-solution and $T_{i}^{(2 a)}$ and $u_{i}^{(2 a)}$ by a known solution as, for example, the analytical solution derived by Westergaard [45]. The same procedure is applicable for auxiliary solution $(2 b)$ to calculate $K_{I I}$.

This theory has shown to yield accurate results for isotropic materials. However, due to different mechanisms responsible for crystallographic crack growth, this concept needs to be modified to be able to describe the observed fracture behaviour in single-crystal nickel-base superalloys as presented in the next chapter. 


\section{Crystallographic Crack Growth Model}

This chapter deals with the central topic of this thesis, namely the proposed crystallographic crack growth methodology, where also the main results are briefly discussed. The incorporation in a finite element-context and a method to account for residual stresses are explained in short. 


\subsection{Crystallographic crack growth}

Previous research has shown that the deformation in single-crystal materials is often localized to a number of crystallographic deformation bands and that cracks follow these bands more easily [15]. Thus, the cracks cannot be expected to follow the conventional Mode I SIF dependency (i.e. crack growth perpendicular to the applied load) as commonly observed in isotropic materials [14, 16-18, 38, 51]. Also, as discussed above, the crack path in single-crystal nickel-base superalloys tends to be very complex including partial growth on crystallographic $\{111\}$-planes. Since this cracking behaviour can deviate substantially from conventional Mode I cracks, the traditional approach to computing the SIFs on the crystallographic planes is not suitable and a more appropriate CDF measure needs to be adopted. A crack growth model for regular Mode I crack growth typically describes the relation between FCGR and SIF-range as in Eq. 2 and is usually based on the conventional Mode I SIF $K_{I}$ as CDF. This holds for most cases where the crack grows orthogonal to the maximum tensile stress. In anisotropic materials like single-crystal nickel-base superalloys this is not necessarily valid, especially for crystallographic cracking. Thus, an appropriate CDF parameter accounting for the anisotropic material behaviour is needed in order to predict the cyclic FCGR in these materials in a similar fashion to Eq. 2. Most research suggests that shear stress intensity factors (as in $K_{I I}$ and $\left.K_{I I I}\right)$ resolved onto a crystallographic plane are suitable candidates [14, 16, 52-54]. This is motivated by the premise that in FCC materials dislocation movement on the crystallographic $\{111\}$-planes resulting from shearing is the predominant slip mode, and these inelastic deformations may eventually lead to damage accumulation resulting in crack initiation and subsequent crack growth.

\subsection{Crystallographic crack driving force}

The above presented M-Integral can be used to compute the SIFs in an anisotropic material. The anisotropic SIFs are then adopted to calculate the stress field around the crack tip using the definitions for anisotropic materials developed by Hoenig [55]. The stresses can then be projected onto the slip planes with the unit normal $\boldsymbol{n}$ into arbitrary unit directions of interest $s$ resulting in a Resolved Stress Intensity Factor (RSIF) as:

$$
\begin{aligned}
& k_{I}(\boldsymbol{n}, \boldsymbol{s})=\lim _{r \rightarrow 0} \sqrt{2 \pi r} \boldsymbol{n} \cdot \boldsymbol{\sigma}(\boldsymbol{s}) \cdot \boldsymbol{n} \\
& k_{I I}(\boldsymbol{n}, \boldsymbol{s})=\lim _{r \rightarrow 0} \sqrt{2 \pi r} \boldsymbol{s} \cdot \boldsymbol{\sigma}(\boldsymbol{s}) \cdot \boldsymbol{n} \\
& k_{I I I}(\boldsymbol{n}, \boldsymbol{s})=\lim _{r \rightarrow 0} \sqrt{2 \pi r} \boldsymbol{t} \cdot \boldsymbol{\sigma}(\boldsymbol{s}) \cdot \boldsymbol{n},
\end{aligned}
$$

where $\boldsymbol{t}=\boldsymbol{n} \times \boldsymbol{s}$ and $\boldsymbol{\sigma}$ is the stress tensor according to [55]. Note that the resolved SIF parameters are denoted by a lower case $k$ in order to distinguish them from the conventional SIF parameter $K$. The parameters $k_{I}, k_{I I}$ and $k_{I I I}$ correspond to the three modes of fracture resolved on an arbitrary plane in the given evaluation directions, $c f$. Fig. 18. A more thorough discussion of the derivation of the RSIFs and 
the appropriate evaluation directions is given in Paper II. Based on the findings and previous research, one reasonable choice is to use the slip directions on the four crystallographic slip planes, $c f$. Table 2. An equivalent SIF parameter $k_{E Q}$, accounting for Resolved Normal Stress (RNS) as well as Resolved Shear Stress (RSS), was formulated and based on the idea that the RSSes weaken the crystallographic plane by dislocation motion and that the RNS separates the surfaces [14]:

$$
k_{E Q}=\sqrt{\psi k_{I}^{2}+k_{I I}^{2}+k_{I I I}^{2}}
$$

where $\psi$ is a calibration parameter scaling the RSIF $k_{I}$ that can be fitted based on experiments. This parameter has been introduced since the influence of the RNSes, which it is associated to, is still unclear and more research is necessary. Sakaguchi et al. [56] published a study on the evaluation of the crystallographic crack growth rate using a damage parameter based on local shear strains calculated by a crystal plasticity approach. They argued that normal stresses do not show any dominant contribution to crystallographic cracking. This can imply that positive RNSes at the crack tip, indicating an open crack, may be sufficient for a valid evaluation of the crystallographic crack growth and thus a Resolved Shear Stress Intensity Factor (RSSIF) parameter in terms of the RSSes can be proposed as:

$$
k_{R S S}=\sqrt{k_{I I}^{2}+k_{I I I}^{2}},
$$

and consequently the Resolved Normal Stress Intensity Factor (RNSIF) is $k_{R N S}=k_{I}$. A more thorough discussion of the choice of an appropriate CDF parameter is given in Papers II, III and IV.

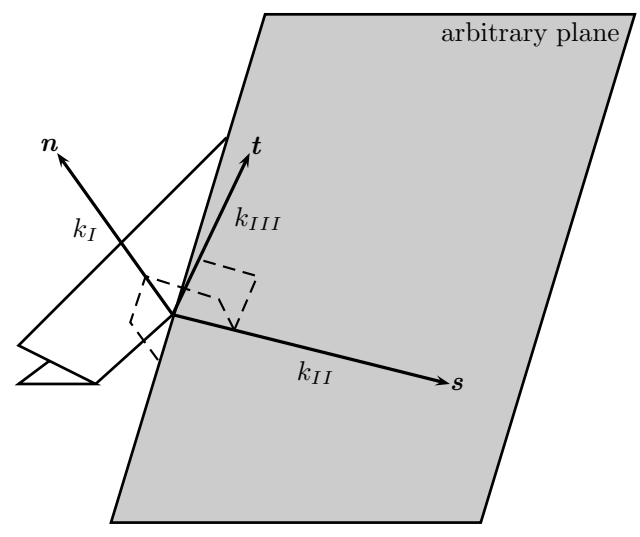

Figure 18: Illustration of the directions associated with the RSIFs. 


\subsection{Crack path prediction}

In industrial components like turbine blades that have complex geometries, e.g. with internal cooling channels and many potential stress raisers, it is of major importance to be able to predict the crack path in order to ensure the structural integrity of the component under the predicted cyclic life time. In the context of this work, it is thus important to be able to predict when a transition from Mode I to crystallographic cracking occurs and onto which of the four crystallographic planes the crack transitions. The transition of cracking modes is discussed in Paper IV and the main finding was that a threshold value of $k_{R S S}$ gave the best indication for a transition of cracking modes for the performed experiments. The maximum $k_{R S S}$ was taken from all slip systems on the experimentally observed crystallographic plane the crack transitioned to. For each specimen, the crack front shape at cracking mode transition was approximated and modelled in an FE-context for the evaluation of $k_{R S S}$. In experiments where heat tints were applied, they were taken as guidance for a better approximation of the crack front shape. An example of a crack shape at transition in a Kb specimen can be seen in Fig. 19. The $k_{R S S}$ values were evaluated along the entire transition crack fronts in a 3D-FE-context. As the transition generally occurs first at a free surface, the mean $k_{R S S}$ value of three nodes in the vicinity of the free surface was evaluated and the results are shown in Fig. 20. Each data point corresponds to the $k_{R S S}$ value at transition for one specimen and also the mean and $95 \%$ confidence interval are given. A conservative criterion was proposed to be that the transition occurs at the threshold value of $k_{R S S} \approx 4.2 \mathrm{MPa} \sqrt{\mathrm{m}}$ based on the lower bound of the $95 \%$ confidence interval as can be seen in Fig. 20 (Kb and DCT). Further details can be found in Paper IV. The prediction of the correct crystallographic plane the crack continues to grow on after a transition of cracking modes is discussed in Paper II. It was found that the selection of the

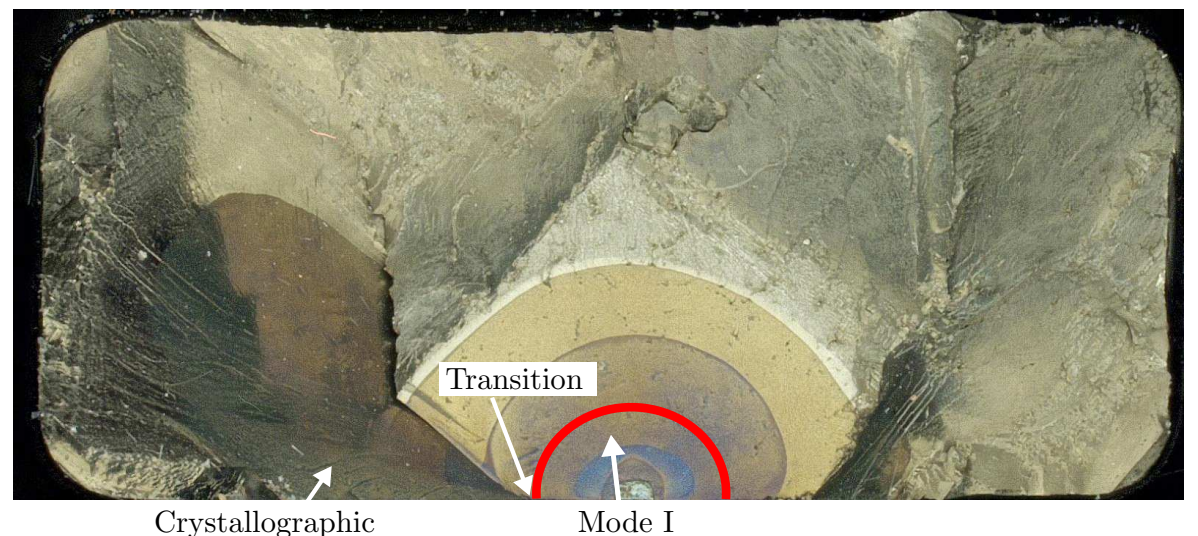

Figure 19: Illustration of the approximated crack front shape (marked in red) at cracking mode transition in a Kb specimen. 


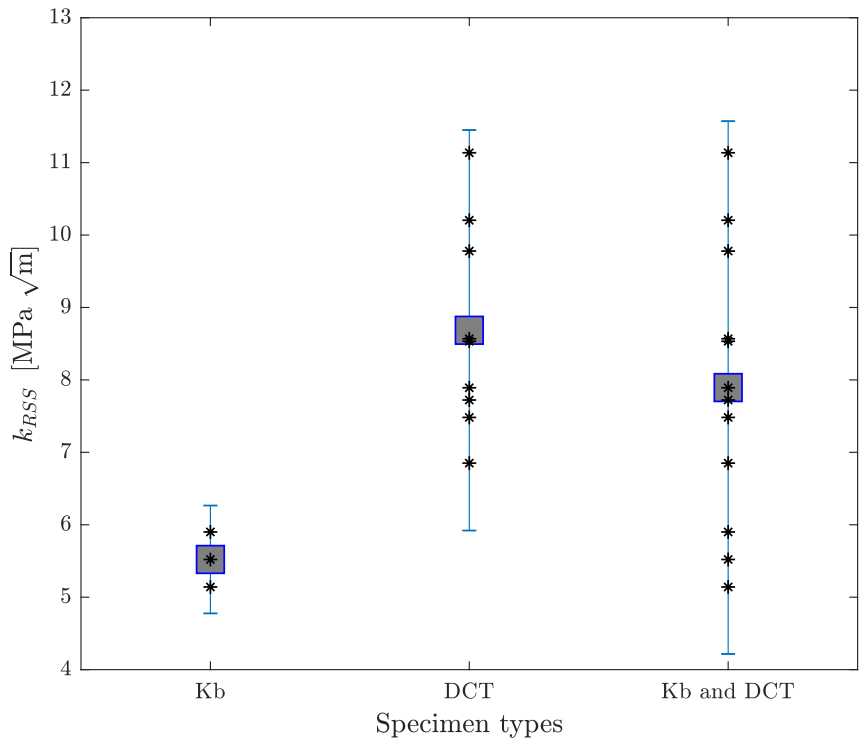

Figure 20: Representation of the mean and 95\% confidence interval of the $k_{R S S}$ values at the cracking mode transition in the vicinity of the free surface with respect to specimen types.

crystallographic plane was predominantly controlled by the maximum $k_{R S S}$ on each potential plane. All three slip directions were evaluated on the respective planes in the positive and negative directions. The main conclusion was that Eq. 16 with $\psi=0.1$ was the CDF parameter that yielded the best prediction for all specimens. The better fit with $\psi=0.1$ compared to $\psi=0$, might be due to scatter or other inaccuracies like the approximation of the crack front shapes. Nevertheless, the RSSIF is deemed to be the most appropriate measure for the prediction of the crystallographic crack path.

\subsection{Crystallographic crack growth modelling}

In order to evaluate the crystallographic FCGR, by a model similar to the one in Eq. 2, simulations and experimental data were utilized to calibrate the needed parameters. The modified crack growth equation relates the crystallographic FCGR to the above presented RSIF-range $\Delta k_{E Q}$ as follows:

$$
\frac{d L}{d N}=C_{c}\left(\Delta k_{E Q}\right)^{n_{c}},
$$

where $L$ is the crystallographic crack length and $C_{c}$ and $n_{c}$ are empirical constants. Further details can be found in Paper III. 

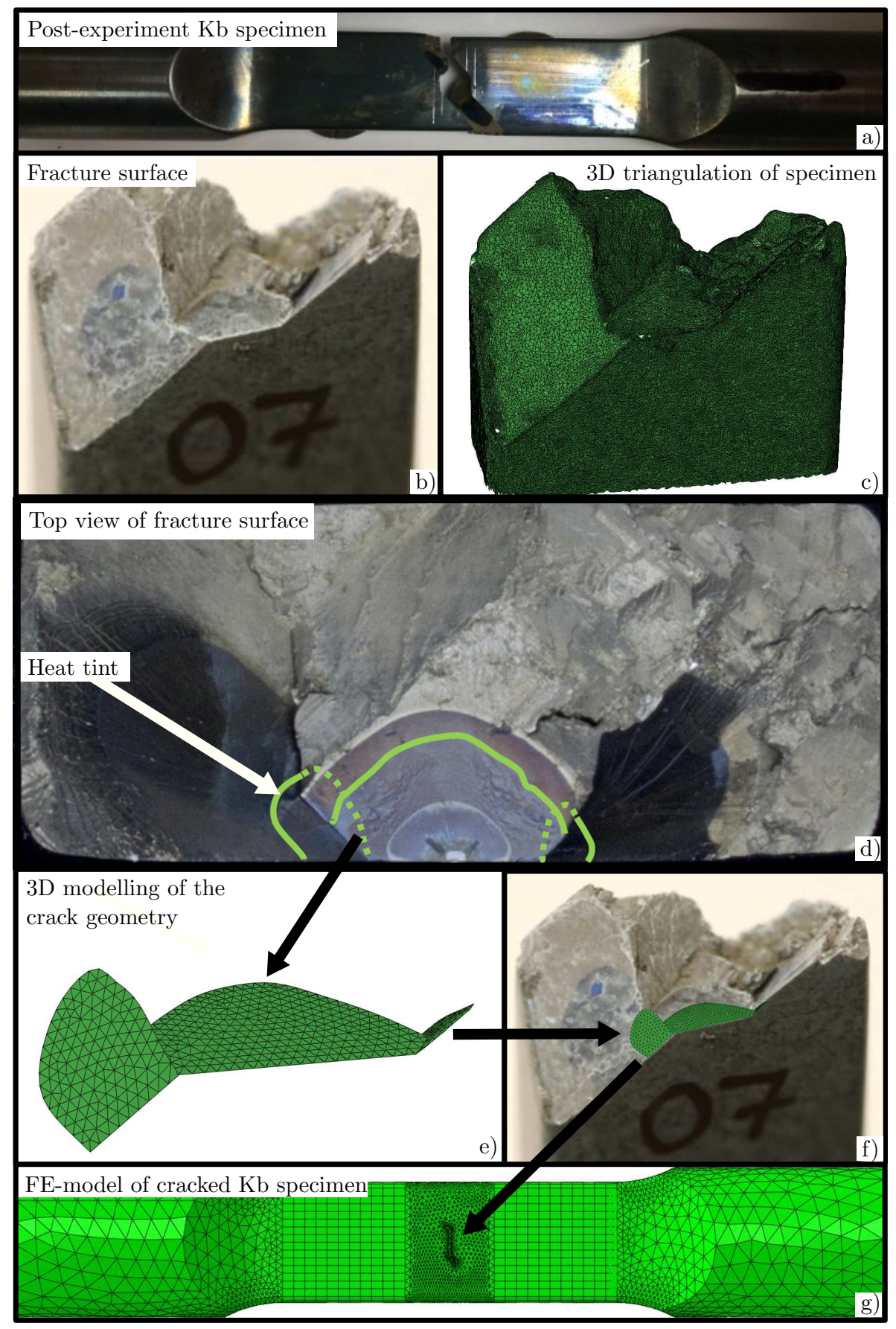

Figure 21: Stepwise overview a) to g) of the procedure to create the FE-models incorporating the crack geometries as indicated by the heat tints. The description of the subfigures are found the in text. 
The RSIFs in Eq. 18 were evaluated by modelling the exact crack geometries as revealed by the above presented heat hints on the fracture surfaces. An overview of this procedure is given in Fig. 21, exemplified with a Kb specimen. An example of a post-experimental Kb specimen with the crack in the centre is given in Fig. 21a). Figs. 21b) and c) show the corresponding fracture surface and the model of the specimen as a 3D triangulation, respectively. A top view of the fracture surface with the highlighted heat tint that was used in the modelling of the crack geometry is shown in Fig. 21d). The information about the crack geometry from Figs. 21c) and d) was used to model the crack geometry shown in Figs. 21e) and f). Finally, the crack was inserted into the FE-model of the Kb specimen to evaluate the RSIFs along the crack front as depicted in Fig. 21g). This procedure was used to evaluate several specimens in order to gather data for the determination of the empirical constants $C_{c}$ and $n_{c}$ in the crack growth model for crystallographic cracking.

Evaluating the RSIFs along all crystallographic crack fronts coupled with the data for the cyclic crack growth from the experiments, $C_{c}$ and $n_{c}$ could be determined to $C_{c}=4.87 \cdot 10^{-8}$ and $n_{c}=4.75$ for $k_{R S S}$ in $\mathrm{MPa} \sqrt{m}$ and $d L / d N$ in $\mathrm{mm} /$ cycle. The results can be seen in Fig. 22. The corresponding trendline for the crystallographic FCGR is shown as a solid black line. The upper and lower bounds of the scatter band were defined by scaling the average trendline by a factor of 5.1, in order to encompass all data points that were assumed to be in the Paris region. For informational purposes also the Mode I data with corresponding trendlines are depicted for the DCT and the Kb specimens but should not be used for comparison as the evaluated CDF parameter is different. The whole evaluation procedure can be found in Paper III.

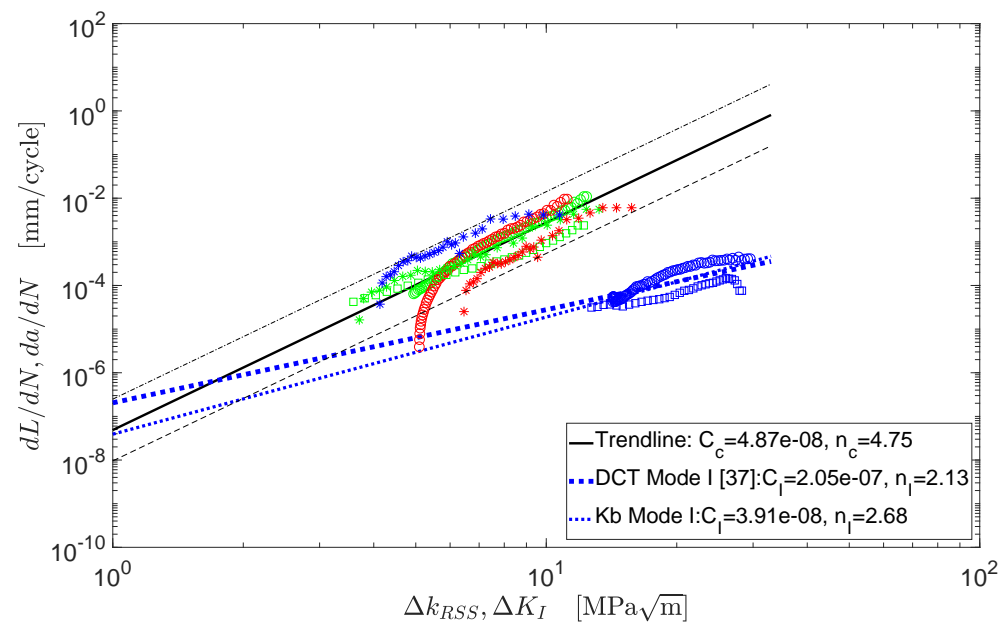

Figure 22: FCGR for crystallographic cracking with $d L / d N$ over $\Delta k_{R S S}$ and for Mode I cracking with $d a / d N$ over $\Delta K_{I}$. Note that a more detailed version of this figure is given in color in the appended Paper III. 


\subsection{Finite element-context}

The above presented methods to evaluate crystallographic crack growth were employed in a 3D-FE-context to enable computations for arbitrary geometries, materials, crystallographic orientations and loading conditions. A crack evaluation software is used to insert the crack in an FE-model, where an appropriate mesh was automatically created enabling a reliable evaluation of the anisotropic SIFs along the crack front. Further details can be found in Paper VI. The employed crack evaluation tool is FRANC3D [57]. In this work, this tool is used in conjunction with the FE-solver ABAQUS [58], which computes the displacement fields used by FRANC3D to evaluate the SIFs along the crack front by the above presented M-Integral. A schematic overview of the procedure is shown in Figure 23. A more detailed description of the procedure can be found in Paper VI. These SIFs are then post-processed in order to calculate the RSIFs; $k_{I}, k_{I I}, k_{I I I}$ and $k_{E Q}$ as presented in Paper III.

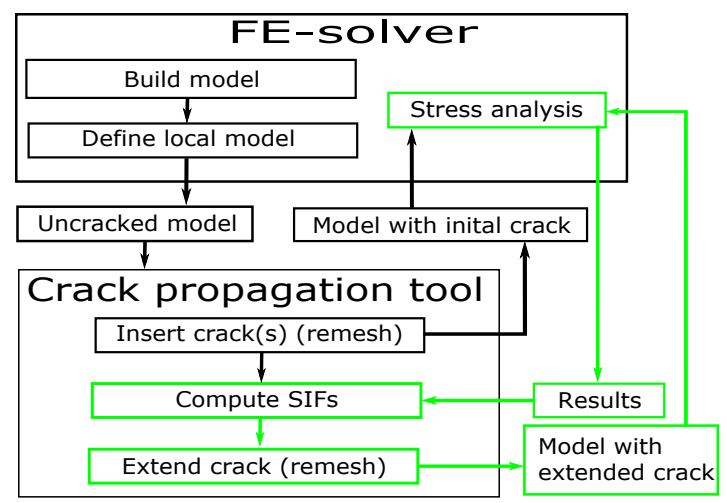

Figure 23: Workflow of crack propagation procedure [59].

\subsection{Handling inelasticity}

The approach to calculate the SIFs by the M-Integral, as presented above, is restricted to linear-elasticity, $c f$. Eqs. 8 and 10. However, often inelastic deformations around e.g. stress concentrations like notches can influence subsequent crack growth in the material by residual stresses and are thus not negligible in crack growth simulations. A method to account for residual stresses caused by inelastic deformations in a linear elastic crack growth context is presented in Paper VI. A residual stress field is extracted from an uncracked FE-model from the end of the first load cycle that reaches a stable hysteresis in an elasto-plastic simulation. The stresses are then superimposed to the linear elastic crack evaluation simulation of the cracked FE-model. This enables to account for inelastic deformations when using the M-Integral to calculate the SIFs. This model is computationally cheaper and 
more stable compared to elasto-plastic crack growth simulations where the crack tip elements can be distorted severely and lead to convergence problems. Further, this enables the evaluation of SIFs which are well established and convenient to use for most applications. This approach is motivated by the assumption that after the initial shakedown no further inelastic deformations are accumulated in the context of the gas turbine applications, e.g. blades or discs [60]. This might not be suitable for different analyses where the hysteresis does not stabilise. In Paper VI, this method was used to predict the cyclic life time of test specimens cast from the turbine disk material IN718 and yielded good results. It should be noted, that the study in Paper VI was done based on the material IN718 in polycrystalline form. However, provided the above mentioned stabilization of the hysteresis, the methodology is expected to be applicable to arbitrary materials, i.e. also single-crystals with certain modifications. It is important that an appropriate material model is chosen in order to capture the correct inelastic behaviour, e.g. such as the one described in [5]. 



\section{Review of Appended Papers}

A brief summary of the six papers appended in Part II is given. Further, it is shown which of the research topics presented in Section 1.2 that were addressed in the respective papers, with the goal to point out the connections between the papers. It should be noted that the papers are not ordered chronologically with respect to publishing date, but they are instead presented following a logical structure. 


\section{Paper I}

A finite element study of the effect of crystal orientation and misalignment on the crack driving force in a single-crystal superalloy

Review: A method is presented that enables the usage of a user defined singlecrystal material model in a finite element-environment, in connection with a crack growth tool. Crack evaluation simulations were performed in a three-dimensional context. The influence of the crystal orientation, as well as the influence of misalignments due to the casting process were investigated. It was shown that both the crystal orientation and the misalignment from the ideal crystal orientation are important for the crack driving force. It can be seen that the crack growth behaviour is highly influenced by the misalignment. Note that an errata has been attached to the paper.

\section{Addressed research topic:}

1. How does the crystallographic orientation influence the crack growth behaviour?

\section{Paper II}

Prediction of crystallographic cracking planes in single-crystal nickelbase superalloys

Review: Two different models to predict the crystallographic cracking planes are presented. They enable the calculation of anisotropic stress intensity factors resolved on crystallographic slip planes in a three-dimensional finite element-context, where material misalignments due to the casting process are accounted for. Furthermore, a method to account for inaccuracies during the determination of the crystallographic orientation is presented. The developed models have been compared to experiments of two different specimen geometries. The results show that a correct prediction of the crystallographic cracking plane could be achieved.

\section{Addressed research topics:}

1. How does the crystallographic orientation influence the crack growth behaviour?

2. What is an appropriate CDF parameter to be used in the context of crystallographic crack growth?

4. How to predict the correct active crystallographic plane after the cracking mode transition? 


\section{Paper III}

Evaluation of the crystallographic fatigue crack growth rate in a single-crystal nickel-base superalloy

Review: A method to evaluate the crystallographic fatigue crack growth rate, which is usually higher compared to Mode I, is presented. The crystallographic crack growth rate was determined by evaluating heat tints on the fracture surfaces of the test specimens from the experiments. Complicated crack geometries including multiple crystallographic crack fronts were modelled in a three-dimensional finite element-context. The data points of the crystallographic fatigue crack growth rate collapse on a narrow scatter band for the crystallographic cracks indicating a correlation with the previously developed crystallographic crack driving force.

\section{Addressed research topic:}

2. What is an appropriate CDF parameter to be used in the context of crystallographic crack growth?

5. What is the crystallographic FCGR?

\section{Paper IV}

Criteria evaluation for the transition of cracking modes in a singlecrystal nickel-base superalloy

Review: An evaluation of cracking mode transition criteria with the purpose to indicate a risk for crystallographic crack growth is presented. As crystallographic cracking is associated with an increased fatigue crack growth rate, it is important to be able to predict the transition. This work evaluates three different criteria that are based on crack driving forces appropriate for crystallographic cracking. The criteria were evaluated in a three-dimensional finite element-context. It is suggested by the results, that a threshold value of a resolved shear stress intensity factor can act as a conservative criterion indicating cracking mode transition. Further, a trend indicating loading frequency dependency could be observed. The models are calibrated and evaluated using isothermal fatigue experiments on two different specimen geometries.

\section{Addressed research topic:}

2. What is an appropriate CDF parameter to be used in the context of crystallographic crack growth?

3. What is a suitable criterion indicating the transition of cracking mode, from growth perpendicular to the loading direction (Mode I) to cracking along the crystallographic slip planes? 


\section{Paper V}

Challenges in crack propagation prediction in single-crystal nickel-base superalloys

Review: This work compiles the challenges that arise in the prediction of crack growth in single-crystal nickel-base superalloys. An emphasis was given towards the increasing complexity associated with more accurate three-dimensional analyses. Challenges associated with testing, modelling and the crack growth prediction were discussed. The objective was to provide an additional viewpoint to engineers and researchers dealing with this highly complex topic, which could benefit the development of more accurate methods for the task of crack propagation prediction in single-crystal nickel-base superalloys.

\section{Addressed research topic:}

1.-5. An overview of most research topics is given and challenges in the context of this research project and in the general literature are discussed.

\section{Paper VI}

Three-dimensional LEFM prediction of fatigue crack propagation in a gas turbine disc material at component near conditions

Review: A method is presented that accounts for plastic rearrangements of stresses and strains, and its incorporation in crack propagation simulations in a linear elastic fracture mechanics context. In order to verify the results, they were compared to a series of LCF tests of notched specimens of the polycrystalline material Inconel 718. The tests involve high strain ranges compared to common fatigue crack propagation tests. In order to have a comparison, purely linear elastic simulations have been performed. The comparison of the stress intensity factors at the crack tip for different crack lengths and computation of the cyclic life-time shows that, for this test set-up, both approaches, i.e. the linear elastic and the method to account for plasticity, gave good results close to the test data.

\section{Addressed research topic:}

6. How to incorporate inelastic effects in the otherwise linear-elastic modelling framework? 


\section{Conclusions and Outlook}

This final chapter of Part I of this dissertation summarises the performed work and presents the main conclusions. Further, an outlook is given towards extensions and improvements on the base of the knowledge gained in this project. 


\subsection{Conclusions}

The main work of this project is the development of an approach to predict the crack growth behaviour of single-crystal nickel-base superalloys with a focus on the crystallographic portion of crack growth.

It can be concluded that for the considered application of the blade fir tree root and the corresponding conditions, i.e. $\mathrm{LCF}$ at $500^{\circ} \mathrm{C}$, a methodology can be provided that enables a conservative cyclic life time prediction of the fatigue crack growth stage accounting for the transition of cracking modes, the prediction of the active crystallographic plane as well as the crystallographic FCGR.

A schematic overview of the papers produced in the project related to the main goal of a framework for fatigue crack growth predictions for single-crystal nickel-base superalloys (for the above mentioned considered application) is depicted in Fig. 24.

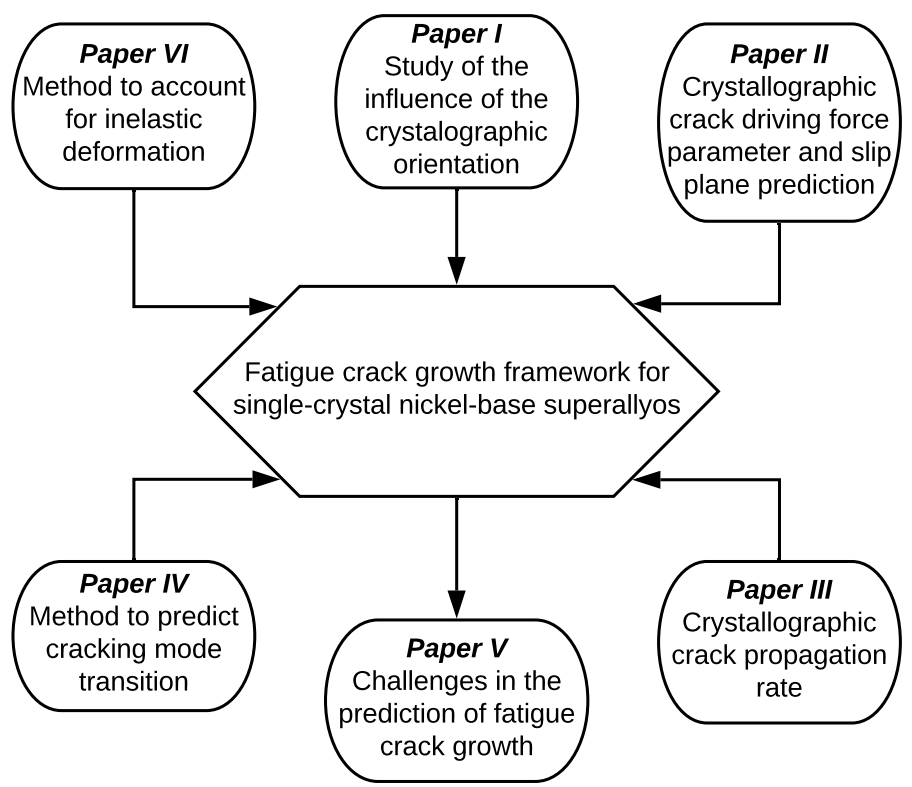

Figure 24: Overview of the project as a whole.

The knowledge gained in this research project can be used to facilitate and improve the transition towards new green energy sources due to the improvements in the fatigue life prediction in relevant gas turbine materials. The ever progressing advancements in the gas turbine technologies, such as better fuel flexibility and higher efficiency can make it the preferred choice when it comes to power generation in a world of renewable energy sources. 


\subsection{Outlook}

Currently, the presented methodology to predict the crack growth behaviour in single-crystal nickel-base superalloys is calibrated to the conditions present at the blade fir tree root, i.e. $\mathrm{LCF}$ at $500{ }^{\circ} \mathrm{C}$. Before expanding the model to different conditions it needs to be assured that good prediction results can be produced by comparisons to corresponding experiments. Further testing on different specimen geometries, with different crystallographic orientations and loading frequencies can improve the presented models and ensure its robustness towards a wider range of applications. Further, the methodology can be extended to account for high temperature effects, such as creep and rafting, that can influence the microstructure and thus the cracking behaviour. Also, different loading conditions as e.g. TMF need to be handled. All this will require further work with respect to testing, material characterisation as well as modelling. Further, several other phenomena, as e.g. crack closure, need by necessity be studied and incorporated.

The goal is to deliver a fatigue crack growth framework for single-crystal nickelbase superalloys to the industry which includes the developed crystallographic crack growth model. This framework can then be implemented into a suitable commercial software, e.g. FRANC3D, which will be able to automatically grow a crack through a mesh and continuously assess the risk for crystallographic crack growth. This model should be simple enough to be handled by any mechanical integrity engineer on an everyday basis. The calculated life until a predicted cracking mode transition can then be used with a relatively small safety margin. This more accurate prediction of the fatigue life will reduce the cost associated with replacement of components and enable longer service intervals resulting in lower cost for the customer. Most importantly, single-crystal materials are often used in rotating components, so it is of high value to be able to assess the failure risk and avoid very costly failures of critical components, or even the whole engine. 



\section{References}

[1] International Energy Agency, "Key World Energy Statistics," tech. rep., 2017.

[2] International Energy Agency, "World Energy Outlook 2018," tech. rep., OECD/IEA, 2018.

[3] A. Pineau and S. D. Antolovich, "High temperature fatigue of nickel-base superalloys - A review with special emphasis on deformation modes and oxidation," Engineering Failure Analysis, vol. 16, no. 8, pp. 2668-2697, 2009.

[4] R. Reed, The Superalloys-Fundamentals and Applications. Cambridge, UK: Cambridge University Press, 2006.

[5] D. Leidermark, J. Moverare, K. Simonsson, S. Sjöström, and S. Johansson, "Room temperature yield behaviour of a single-crystal nickel-base superalloy with tension/compression asymmetry," Computational Materials Science, vol. 47, no. 2, pp. 366-372, 2009.

[6] D. P. Pope and S. S. Ezz, "Mechanical properties of Ni3Al and nickel-base alloys with high volume fraction of gamma prime," International metals reviews, vol. 29, no. 3, pp. 136-167, 1984.

[7] M. Segersäll, J. Moverare, D. Leidermark, and K. Simonsson, "Low-cycle fatigue behaviour of a Ni-based single-crystal superalloy," Advanced Materials Research, vol. 891-892, 2014.

[8] R. Naik, D. DeLuca, and D. Shah, "Critical plane fatigue modeling and characterization of single crystal nickel superalloys," Journal of Engineering for Gas Turbines and Power, vol. 126, no. 2, 2004.

[9] D. Leidermark and M. Segersäll, "Modelling of thermomechanical fatigue stress relaxation in a single-crystal nickel-base superalloy," Computational Materials Science, vol. 90, pp. 61-70, 2014.

[10] R. L. Amaro, S. D. Antolovich, R. W. Neu, and A. Staroselsky, "Physics-Based Modeling of Thermo-Mechanical Fatigue in PWA 1484," in Superalloys 2012, pp. 481-490, 2012.

[11] J. Moverare and R. Reed, "Thermomechanical fatigue in single crystal superalloys," in MATEC Web of Conferences, vol. 14, 2014. 
[12] M. Segersäll, J. J. Moverare, D. Leidermark, and K. Simonsson, "Creep and stress relaxation anisotropy of a single-crystal superalloy," Metallurgical and Materials Transactions A: Physical Metallurgy and Materials Science, vol. 45, no. 5, pp. 2532-2544, 2014.

[13] J.-B. Le Graverend, J. Cormier, F. Gallerneau, P. Villechaise, S. Kruch, and J. Mendez, "A microstructure-sensitive constitutive modeling of the inelastic behavior of single crystal nickel-based superalloys at very high temperature," International Journal of Plasticity, vol. 59, 2014.

[14] J. Telesman and L. J. Ghosn, "Fatigue crack growth behavior of PWA 1484 single crystal superalloy at elevated temperatures," Journal of Engineering for Gas Turbines and Power, vol. 118, no. 2, pp. 399-405, 1996.

[15] D. Leidermark, J. Moverare, K. Simonsson, and S. Sjöström, "A combined critical plane and critical distance approach for predicting fatigue crack initiation in notched single-crystal superalloy components," International Journal of Fatigue, vol. 33, no. 10, pp. 1351-1359, 2011.

[16] T. Tinga, "Stress intensity factors and crack propagation in a single crystal nickel-based superalloy," Engineering Fracture Mechanics, vol. 73, no. 12, pp. 1679-1692, 2006.

[17] H. Kagawa and Y. Mukai, "The Effect of Crystal Orientation and Temperature on Fatigue Crack Growth of Ni-Based Single Crystal Superalloy," in Superalloys 2012, pp. 225-233, John Wiley and Sons, oct 2012.

[18] K. S. Chan, J. Feiger, Y. D. Lee, R. John, and S. J. Hudak, "Fatigue crack growth thresholds of deflected mixed-mode cracks in PWA1484," vol. 127, pp. 2-7, jan 2005 .

[19] R. W. Neu, "Crack paths in single-crystal Ni-base superalloys under isothermal and thermomechanical fatigue," International Journal of Fatigue, vol. 123, pp. 268-278, jun 2019.

[20] C. Busse, Aspect of Crack Growth in Single-Crystal Nickel-Base Superalloys. PhD thesis, Linköping University, 2017.

[21] H. Rick, Gasturbinen und Flugantriebe. Springer, 2013.

[22] R. Reed, J. Moverare, A. Sato, F. Karlsson, and M. Hasselqvist, "A New Single Crystal Superalloy for Power Generation Applications," in Superalloys 2012, pp. 197-204, 2012.

[23] E. S. Fisher, "On the elastic moduli of nickel rich NiAl alloy single crystals," Scripta Metallurgica, 1986.

[24] R. Eriksson, Thermal Barrier Coatings. PhD thesis, Linköping University, 2013. 
[25] R. C. Reed, T. Tao, and N. Warnken, "Alloys-By-Design: Application to nickel-based single crystal superalloys," Acta Materialia, 2009.

[26] T. M. Pollock and S. Tin, "Nickel-based superalloys for advanced turbine engines: Chemistry, microstructure, and properties," Journal of Propulsion and Power, 2006.

[27] M. Durand-Charre, The Microstructure of Superalloys. Amsterdam: Gordon and Breach Publishers, 1997.

[28] A. Sato, J. J. Moverare, M. Hasselqvist, and R. C. Reed, "On the Mechanical Behavior of a New Single-Crystal Superalloy for Industrial Gas Turbine Applications," Metallurgical and Materials Transactions A, vol. 43, no. 7, pp. 2302-2315, 2012.

[29] C. Busse, J. Homs, D. Gustafsson, F. Palmert, B. Sjödin, J. Moverare, K. Simonsson, and D. Leidermark, "A finite element study of the effect of crystal orientation and misalignment on the crack driving force in a single-crystal superalloy," in Proceedings of the ASME Turbo Expo, vol. 7A-2016, 2016.

[30] N. K. Arakere, S. Siddiqui, S. Magnan, F. Ebrahimi, and L. E. Forero, "Investigation of three-dimensional stress fields and slip systems for fcc single-crystal superalloy notched specimens," vol. 127, pp. 629-637, may 2005.

[31] Y. Zhang, W. Qiu, H.-J. Shi, C. Li, K. Kadau, and O. Luesebrink, "Effects of secondary orientations on long fatigue crack growth in a single crystal superalloy," Engineering Fracture Mechanics, vol. 136, pp. 172-184, 2015.

[32] M. Sakaguchi, R. Komamura, Y. Hosaka, and H. Inoue, "Stage I Fatigue Crack Propagation in a Single Crystal and a Directional Solidified Ni-Base Superalloy," in Superalloys 2016, 2016.

[33] N. Hou, W. Gou, Z. Wen, and Z. Yue, "The influence of crystal orientations on fatigue life of single crystal cooled turbine blade," Materials Science and Engineering: A, vol. 492, no. 1-2, pp. 413-418, 2008.

[34] M. Segersäll, D. Leidermark, and J. J. Moverare, "Influence of crystal orientation on the thermomechanical fatigue behaviour in a single-crystal superalloy," Materials Science and Engineering A, vol. 623, pp. 68-77, 2015.

[35] D. MacLachlan and D. Knowles, "Fatigue behaviour and lifing of two single crystal superalloys," Fatigue and Fracture of Engineering Materials and Structures, vol. 24, no. 8, 2001.

[36] C. Busse, F. Palmert, B. Sjödin, P. Almroth, D. Gustafsson, K. Simonsson, and D. Leidermark, "Evaluation of the crystallographic fatigue crack growth rate in a single-crystal nickel-base superalloy," International Journal of Fatigue, vol. 127 , pp. 259-267, oct 2019. 
[37] F. Palmert, J. Moverare, D. Gustafsson, and C. Busse, "Fatigue crack growth behaviour of an alternative single crystal nickel base superalloy," International Journal of Fatigue, vol. 109, pp. 166-181, apr 2018.

[38] B. F. Antolovich, A. Saxena, and S. D. Antolovich, "Fatigue crack propagation in single-crystal CMSX- 2 at elevated temperature," Journal of Materials Engineering and Performance, vol. 2, no. 4, pp. 489-495, 1993.

[39] A. Coles, R. E. Johnson, and H. G. Popp, "Utility of surface-flawed tensile bars in cyclic life studies," Journal of Engineering Materials and Technology, Transactions of the ASME, vol. 98, no. 4, pp. 305-315, 1976.

[40] ASTM, "Test Method for Measurement of Fatigue Crack Growth Rates," tech. rep., 2012.

[41] P. C. Paris, M. P. Gomez, and W. E. Anderson, "A Rational Analytic Theory of Fatigue," The trend in Engineering, vol. 13, pp. 9-14, 1961.

[42] P. C. Paris and F. Erdogan, "A Critical Analysis of Crack Propagation Laws," Journal of Basic Engineering, vol. 85, no. 4, p. 528, 1963.

[43] W. Elber, "Fatigue crack closure under cyclic tension," Engineering Fracture Mechanics, 1970.

[44] R. Forman and S. R. Mettu, "Behavior of Surface and Corner Cracks Subjected to Tensile and Bending Loads in a Ti-6Al-4V Alloy," Fracture Mechanics: Twenty-Second Symposium (Volume 1), ASTM STP 1131, 1992.

[45] H. M. Westergaard, "Bearing pressures and cracks," Journal of Applied Mechanics, vol. 61, pp. A49-A53, 1939.

[46] G. Irwin, "Onset of Fast Crack Propagation in High Strength Steel and Aluminum Alloys," in Sagamore Research Conference Proceedings, no. May 1956, pp. 289-305, 1956.

[47] C. Busse, F. Palmert, B. Sjödin, P. Almroth, D. Gustafsson, K. Simonsson, and D. Leidermark, "Prediction of crystallographic cracking planes in single-crystal nickel-base superalloys," Engineering Fracture Mechanics, vol. 196, pp. 206-223, jun 2018.

[48] J. F. Yau, S. S. Wang, and H. T. Corten, "A Mixed-Mode Crack Analysis of Isotropic Solids Using Conservation Laws of Elasticity," Journal of Applied Mechanics, vol. 47, no. 2, p. 335, 1980.

[49] P. A. Wawrzynek, B. J. Carter, and L. Banks-Sills, "The M-integral for computing stress intensity factors in generally anisotropic materials," tech. rep., Huntsville, USA, 2005. 
[50] L. Banks-Sills, P. A. Wawrzynek, B. Carter, A. R. Ingraffea, and I. Hershkovitz, "Methods for calculating stress intensity factors in anisotropic materials: Part IIArbitrary geometry," Engineering Fracture Mechanics, vol. 74, no. 8, pp. 12931307, 2007.

[51] D. J. Duquette, M. Gell, and J. W. Piteo, "A Fractographic Study of Stage I Fatigue Cracking in a Nickel-Base Superalloy Single Crystal," Metallurgical Transactions, vol. 1, no. 11, pp. 3107-3115, 1970.

[52] M. Gell and G. Leverant, "The characteristics of stage I fatigue fracture in a highstrength nickel alloy," Acta Metallurgica, vol. 16, no. 4, pp. 553-561, 1968.

[53] S. Ranjan and N. K. Arakere, "A Fracture-Mechanics-Based Methodology for Fatigue Life Prediction of Single Crystal Nickel-Based Superalloys," Journal of Engineering for Gas Turbines and Power, vol. 130, no. 3, p. 032501, 2008.

[54] W. Qiu, X. Ma, S. Rui, and H.-J. Shi, "Crystallographic analysis on small fatigue crack propagation behaviour of a nickel-based single crystal superalloy," Fatigue and Fracture of Engineering Materials and Structures, vol. 40, no. 1, 2017.

[55] A. Hoenig, "Near-tip behavior of a crack in a plane anisotropic elastic body," Engineering Fracture Mechanics, vol. 16, no. 3, pp. 393-403, 1982.

[56] M. Sakaguchi, R. Komamura, X. Chen, M. Higaki, and H. Inoue, "Crystal plasticity assessment of crystallographic Stage I crack propagation in a Ni-based single crystal superalloy," International Journal of Fatigue, 2019.

[57] FRANC3D, FRANC3D Reference Manual. Ithaca, USA: Fracture Analysis Consultants Inc., 2016.

[58] ABAQUS, ABAQUS 6.12 Documentation. Providence, USA: Dassault Systèmes, 2014.

[59] C. Busse, D. Gustafsson, P. Rasmusson, B. Sjödin, J. J. Moverare, K. Simonsson, and D. Leidermark, "Three-Dimensional LEFM Prediction of Fatigue Crack Propagation in a Gas Turbine Disk Material at Component Near Conditions," Journal of Engineering for Gas Turbines and Power, vol. 138, no. 4, p. 042506, 2015 .

[60] P. Almroth and D. Gustafsson, "On Thermomechanical Fatigue Crack Growth Analysis in Gas Turbine Blading in a 3D Finite Element Context," Eighth International Conference on Low Cycle Fatigue, 2017. 



\section{Part II}

Appended Papers 



\section{Papers}

The papers associated with this thesis have been removed for copyright reasons. For more details about these see:

http://urn.kb.se/resolve?urn=urn:nbn:se:liu:diva-160477 


\section{FACULTY OF SCIENCE AND ENGINEERING}

Linköping Studies in Science and Technology

Dissertations No. 2023, 2019

Solid Mechanics

Linköping University

SE-581 83 Linköping, Sweden

www.liu.se

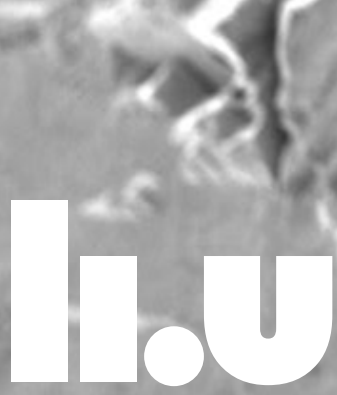

